\title{
Universidade de São Paulo - USP
}

Escola de Enfermagem de Ribeirão Preto - EERP

Programa de Pós-Graduação em Enfermagem Psiquiátrica

\section{CULTURA E CLIMA ORGANIZACIONAL E SUA RELAÇÃO COM O ESTRESSE ENTRE PROFISSIONAIS DE UM SERVIÇO DE EMERGÊNCIA}

Dissertação apresentada à Escola de Enfermagem de Ribeirão Preto (EERP) da Universidade de São Paulo para obtenção do título de Mestre em Enfermagem no Programa de Mestrado de Enfermagem Psiquiátrica.

Linha de Pesquisa: Promoção de Saúde Mental

\author{
Aluna: Maria Tereza Signorini Santos \\ Orientador: Profa. Dra. Lucilene Cardoso
}

\section{Ribeirão Preto}


Maria Tereza Signorini Santos

\title{
CULTURA E CLIMA ORGANIZACIONAL E SUA RELAÇÃO COM O ESTRESSE ENTRE PROFISSIONAIS DE UM SERVIÇO DE EMERGÊNCIA
}

\author{
Versão Original
}

Dissertação apresentada à Escola de Enfermagem de Ribeirão Preto (EERP) da Universidade de São Paulo para obtenção do título de Mestre em Enfermagem no Programa de Mestrado de Enfermagem Psiquiátrica.

Linha de Pesquisa: Promoção de Saúde Mental

Orientadora: Profa. Dra. Lucilene Cardoso

Ribeirão Preto 
Autorizo a reprodução e divulgação total ou parcial deste trabalho, por qualquer meio convencional ou eletrônico, para fins de estudo e pesquisa, desde que citada a fonte.

Santos, Maria Tereza Signorini Santos

Cultura e clima organizacional e sua relação com o estresse entre profissionais de um serviço de emergência / Maria Tereza Signorini Santos Santos, - Ribeirão Preto, 2018. 87 f.

Orientadora: Lucilene Cardoso Cardoso.

Tese (Mestrado - Enfermagem Psiquiátrica) - Universidade de São Paulo, Escola de Enfermagem de Ribeirão Preto, 2018.

1. Promoção de Saúde Mental. 
SANTOS, Maria Tereza Signorini

\section{CULTURA E CLIMA ORGANIZACIONAL E SUA RELAÇÃO COM O ESTRESSE ENTRE PROFISSIONAIS DE UM SERVIÇO DE EMERGÊNCIA}

Dissertação apresentada à Escola de Enfermagem de Ribeirão Preto (EERP) da Universidade de São Paulo para obtenção do título de Mestre em Enfermagem no Programa de Mestrado de Enfermagem Psiquiátrica.

Linha de Pesquisa: Promoção de Saúde Mental

\section{Aprovado em:}

\section{Banca Examinadora}

Prof. Dr.

Instituição:

Julgamento:

Prof. Dr.

Instituição:

Julgamento:

Prof. Dr.

Instituição:

Julgamento: 
À DEUS que sempre me guiou a cada decisão. Dedico esse trabalho aos meus pais (Dorival e Terezinha) e irmãos, com todo meu amor e gratidão, por tudo que fizeram e fazem por mim. Desejo poder ser merecedora do esforço dedicado por vocês em todos os aspectos, especialmente quanto à minha formação e caráter. Aos meus irmãos que me apoiaram e me ajudaram sempre que necessário e estão presentes em todas as minhas conquistas. 


\section{AGRADECIMENTO ESPECIAL}

A minha orientadora Lucilene Cardoso,

Que muitas vezes foi muito mais que orientadora,

me aconselhando, apoiando em escolha e acima de tudo acreditando no meu potencial.

Não tenho palavras para descrever o quanto te admiro como pessoa e especialmente como professora! 


\section{AGRADECIMENTOS}

Agradeço a minha orientadora Profa. Dra. Lucilene Cardoso por ter me recebido e sempre me mostrado o caminho correto a ser seguido, de forma única, admirável e exemplar. Desejo poder contribuir à ciência e ao universo acadêmico com a mesma ética e entusiasmo que me transmitiu. Espero também que nossas agradáveis conversas tenham vida longa e que essa parceria que nos uniu na graduação perpetue por toda a nossa vida, estendo o meu agradecimento ao seu esposo William, que se demonstrou compreensivo quanto aos momentos de sua esposa dedicado ao meu crescimento.

Registro também meu agradecimento a Prof. Dr. Gerson Pereira Alves Junior, pelos importantes direcionamentos passados, desde o início de minha busca pelo programa de mestrado até a conclusão desse projeto.

Agradeço a Profa. Dra. Sueli Aparecida Frari Galera por ter me recebido e orientado no início desse caminho acadêmico e se mostrou sempre disposta e presente.

Da mesma forma, agradeço as minhas queridas amigas, Enfermeira Mestre Juceli, Enfermeira Mestre Tássia e Enfermeira Doutora Sandra que me apoiaram e me auxiliaram em diversos momentos da elaboração e desenvolvimento desse projeto, meus sinceros agradecimentos.

Não posso deixar de agradecer aos meus amigos e familiares por compreenderem minha ausência em certos momentos e principalmente pelo estímulo constante, contribuindo assim em mais essa etapa da minha vida.

Antes de terminar, agradeço todo auxílio e paciência da equipe de pós-graduação da Escola de Enfermagem de Ribeirão Preto, em especial, Vinícius Nori, Jonas Bodini Alonso e Adriana Borela.

Por fim, agradeço aos voluntários que foram avaliados e aos responsáveis pelo mesmo que permitiriam as avaliações para o desenvolvimento desse trabalho. 
"Não precisamos de mais dinheiro, não precisamos de mais sucesso ou fama, não precisamos do corpo perfeito, nem mesmo do parceiro perfeito, agora mesmo, neste momento exato, dispomos da mente, que é todo o equipamento básico de que precisamos para alcançar a plena felicidade.” 


\section{RESUMO}

SANTOS, M. T. S. Cultura e clima organizacional e sua relação com o estresse entre profissionais de um serviço de emergência. 2018. p.87. Tese (Mestrado) - Escola de Enfermagem de Ribeirão Preto, Universidade de São Paulo, Ribeirão Preto, 2018.

Introdução: Os profissionais que atuam na área de emergência lidam constantemente com diversas mudanças, tornando uma área de atuação que exige muito dos profissionais. Estima-se que o estresse afete mais de $90 \%$ da população mundial e que, por não ser considerada uma doença em si, é subestimado, tendo como consequência a ausência de tratamentos e prevenção ao adoecimento. Entende-se cultura organizacional condutas experimentais e símbolo em processo de assimilação, padrões e hábitos razoavelmente estabelecidos. Clima organizacional é o indicador do grau de satisfação dos membros de uma empresa, em relação a diferentes aspectos da cultura ou realidade aparente da organização. O estresse pode ocasionar graves consequências e entre trabalhadores em saúde sua ocorrência ainda carece ser avaliada em estudos ampliados que contemplem sua complexidade de maneira mais abrangente, considerando fatores pessoas, ambientais e psicossociais. Dessa forma, avaliar o clima e cultura organizacional é importância para entender como funcionam as instituições, quais são os pontos fortes e frágeis do local e assim propor melhorias aos pontos frágeis e potencializar os pontos fortes. Objetivo: O objetivo do estudo é identificar o clima e a cultura organizacional de uma organização de um serviço hospitalar de emergência e sua relação com a prevalência de estresse. Métodos: Foi desenvolvido um estudo transversal, analítico, exploratório, de abordagem quantitativa. Em um serviço público de emergência de Ribeirão Preto. A amostra do estudo foi constituída por 155 participantes. O estudo foi realizado no período de janeiro de 2016 a outubro de 2018, em um serviço público de emergência de Ribeirão Preto/SP. Resultados: Na amostra estudada observou-se 47,1\% de

profissionais com estresse atual, sendo que entre estes profissionais que tinham estresse: $82,2 \%$ eram mulheres. Os resultados evidenciaram que os profissionais com estresse estavam em sua maioria na fase de resistência $(76,7 \%), 17,8 \%$ na fase de quase-exaustão, 4,1\% na fase de exaustão e $1,4 \%$ na fase de alerta. Destaca-se maiores escores médios relacionados à cultura organizacional e o estresse atual, notadamente no fator 2 "Rigidez na estrutura hierárquica de 
poder" (média 3,02 \pm dp 0,77) e no fator 3 "Profissionalismo competitivo e individualista" $(2,28$ \pm dp 0,66). Destaca-se maiores escores médios do clima organizacional e o estresse atual no fator 1 "Apoio da chefia e da organização" (média 2,69 \pm dp 0,71), fator 2 "Recompensa" (1,91 $\pm d p$ $0,63)$, fator 3 "Conforto físico" $(2,97 \pm d p$ 0,84) e fator 5 "Coesão entre colegas" $(2,95 \pm d p$ 0,72). Os resultados evidenciaram que nas análises entre o estresse com as variáveis sóciodemográficas e de trabalho, apenas a variável sexo esteve associada com o estresse, já nas análises entre cultura e clima organizacional houve correlação estatisticamente significativa entre o fator 1 - "Profissionalismo cooperativo", 4 - "Satisfação e bem-estar dos empregados", 5 "Práticas de integração externa" e 6 - "Práticas de recompensa e treinamento" da cultura organizacional com todos os fatores do clima organizacional (Apoio da chefia e da organização, Recompensa, Conforto físico, Controle/Pressão e Coesão entre colegas), todas com um nível de significância abaixo de 0,01 . No teste da regressão foi possível observar a relação do estresse com as variáveis: sexo (p 0,017; $\operatorname{Exp(B)~2,766),~vínculo~empregatício~(p~0,049;~} \operatorname{Exp(B)~1,403)~e~}$

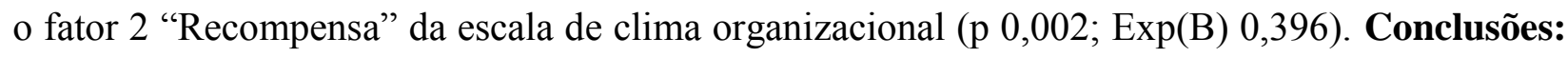
O presente estudo possibilitou concluir a influencia da cultura e clima organizacional de uma organização de saúde hospitalar de emergência e sua relação com a prevalência de estresse. Também identificou a ligação entre cultura e clima organizacional, mostrando a influência da cultura sobre o clima organizacional.

Palavras chaves: Cultura Organizacional; Clima Organizacional; Estresse; Urgência e Emergência; Profissionais da Saúde. 


\begin{abstract}
SANTOS, M. T. S. Culture and organizational climate and its relation with the stress among professionals of an emergency service. 2018. p.87. Thesis (Master degree) - School of Nursing of Ribeirão Preto, University of São Paulo, Ribeirão Preto, 2018.
\end{abstract}

Introduction: The professionals who work in the emergency area constantly deal with several changes, making it an area of practice that demands a lot of professionals. It is estimated that stress affects more than $90 \%$ of the world population and, because it is not considered a disease in itself, is underestimated, resulting in the absence of treatments and prevention of illness. Organizational culture is understood as experimental conduct and symbol in process of assimilation, patterns and habits reasonably established. Organizational climate is the indicator of the degree of satisfaction of the members of a company, in relation to different aspects of the culture or apparent reality of the organization. Stress can cause serious consequences and among health workers, its occurrence still needs to be evaluated in expanded studies that contemplate its complexity in a more comprehensive way, considering personal, environmental and psychosocial factors. Thus, assessing the climate and organizational culture is important to understand how the institutions work, what are the strengths and weaknesses of the site and thus propose improvements to the fragile points and potentiate the strengths. Objective: The objective of the study is to identify the organizational climate and organizational culture of an emergency hospital service and its relation to the prevalence of stress. Methods: A transversal, analytical, exploratory, quantitative approach was developed. In an emergency public service of Ribeirão Preto. The study sample consisted of 155 participants. The study was conducted from January 2016 to October 2018, in a public emergency service in Ribeirão Preto / SP. Results: In the sample studied, $47.1 \%$ of professionals with current stress were present, and among these professionals who had stress: $82.2 \%$ were women. The results showed that the professionals with stress were mostly in the resistance phase (76.7\%), $17.8 \%$ in the near-exhaustion phase, $4.1 \%$ in the exhaustion phase and $1.4 \%$ in the phase of exhaustion. alert. It is worth mentioning that higher scores are related to organizational culture and current stress, especially in factor 2 
"Rigidity in the hierarchical structure of power" (average $3.02+\mathrm{dp} 0.77$ ) and factor 3 "Competitive and individualistic professionalism" (2, $28+\mathrm{dp}$ 0.66). It is worth noting the higher average scores of the organizational climate and the current stress in the factor 1 "Support of management and organization" (average $2.69+\mathrm{dp} 0.71)$, factor 2 "Reward" (1.91 + dp 0.63 ), factor 3 "Physical comfort" (2.97 + dp 0.84) and factor 5 "Cohesion among colleagues" (2.95 + dp 0.72). The results showed that in the analyzes between stress and socio-demographic and work variables, only the gender variable was associated with stress. In the analyzes between culture and organizational climate, there was a statistically significant correlation between factor 1 "Cooperative professionalism" , 4 - "Employees' satisfaction and well-being", 5 - "External integration practices" and 6 - "Reward and training practices" of organizational culture with all organizational climate factors (Support of leadership and organization, Reward, Physical Comfort, Control / Pressure and Cohesion among colleagues), all with a level of significance below 0.01. In the regression test, it was possible to observe the relationship of stress with the variables: sex (p 0.017, Exp (B) 2,766), employment bond (p 0.049, Exp (B) 1,403) and factor 2 "Reward" organizational (p 0.002; Exp (B) 0.396). Conclusions: The present study made it possible to conclude the influence of the organizational culture and climate of an emergency hospital health organization and its relation with the prevalence of stress. It also identified the link between culture and organizational climate, showing the influence of culture on the organizational

climate.

Keywords: Organizational Culture; Organizational Climate; Stress; Urgency and emergency; Health professionals. 


\section{RESUMEN}

SANTOS, M. T. S. Cultura y clima organizacional y su relación con el estrés entre profesionales de un servicio de emergencia. 2018. p.87. Tesis (Maestría) - Escuela de Enfermería de Ribeirão Preto, Universidad de São Paulo, Ribeirão Preto, 2018.

Introducción: Los profesionales que actúan en el área de emergencia tratan constantemente con diversos cambios, haciendo un área de actuación que exige mucho de los profesionales. Se estima que el estrés afecta más del $90 \%$ de la población mundial y que, por no ser considerada una enfermedad en sí, es subestimado, teniendo como consecuencia la ausencia de tratamientos y prevención al enfermo. Se entiende cultura organizacional conductas experimentales y símbolo en proceso de asimilación, patrones y hábitos razonablemente establecidos. El clima organizacional es el indicador del grado de satisfacción de los miembros de una empresa, en relación a diferentes aspectos de la cultura o realidad aparente de la organización. El estrés puede ocasionar graves consecuencias y entre trabajadores en salud su ocurrencia todavía carece de ser evaluada en estudios ampliados que contemplen su complejidad de manera más amplia, considerando factores personas, ambientales y psicosociales. De esta forma, evaluar el clima y la cultura organizacional es importante para entender cómo funcionan las instituciones, cuáles son los puntos fuertes y frágiles del lugar y así proponer mejoras a los puntos frágiles y potenciar los puntos fuertes. Objetivo: El objetivo del estudio es identificar el clima y la cultura organizacional de una organización de un servicio hospitalario de emergencia y su relación con la prevalencia de estrés. Métodos: Se desarrolló un estudio transversal, analítico, exploratorio, de abordaje cuantitativo. En un servicio público de emergencia de Ribeirão Preto. La muestra del estudio fue constituida por 155 participantes. El estudio se realizó en el período de enero de 2016 a octubre de 2018, en un servicio público de emergencia de Ribeirão Preto / SP. Resultados: En la muestra estudiada se observó el $47,1 \%$ de profesionales con estrés actual, siendo que entre estos profesionales que tenían estrés: el 82,2\% eran mujeres. Los resultados evidenciaron que los 
profesionales con estrés estaban en su mayoría en la fase de resistencia (76,7\%), el 17,8\% en la fase de casi-agotamiento, el 4,1\% en la fase de agotamiento y el 1,4\% en la fase de agotamiento alerta. Se destacan mayores escores medios relacionados a la cultura organizacional y el estrés actual, notadamente en el factor 2 "Rigidez en la estructura jerárquica de poder" (promedio 3,02 + dp 0,77) y en el factor 3 "Profesionalismo competitivo e individualista" (2), $28+$ dp 0,66). Se destacan mayores escores medios del clima organizacional y el estrés actual en el factor 1 "Apoyo de la jefatura y de la organización" (promedio 2,69 + dp 0,71), factor 2 "Recompensa" $(1,91+\mathrm{dp}$ 0,63) ), factor 3 "Confort físico" $(2,97$ + dp 0,84) y factor 5 "Cohesión entre colegas" $(2,95+\mathrm{dp}$ 0,72). Los resultados evidenciaron que en los análisis entre el estrés con las variables sociodemográficas y de trabajo, sólo la variable sexo estuvo asociada con el estrés, ya en los análisis entre cultura y clima organizacional hubo correlación estadísticamente significativa entre el factor 1 - "Profesionalismo cooperativo" , 4 - "Satisfacción y bienestar de los empleados", 5 "Prácticas de integración externa" y 6 - "Prácticas de recompensa y entrenamiento" de la cultura organizacional con todos los factores del clima organizacional (Apoyo de la jefatura y de la organización, Recompensa , Confort físico, Control / Presión y Cohesión entre colegas), todas con un nivel de significancia por debajo de 0,01. En la prueba de regresión fue posible observar la relación del estrés con las variables: sexo (p 0,017, Exp (B) 2,766), vínculo laboral (p 0,049, Exp (B) 1,403) y el factor 2 "Recompensa" de la escala de clima (p 0,002, Exp (B) 0,396). Conclusiones: El presente estudio posibilitó concluir la influencia de la cultura y clima organizacional de una organización de salud hospitalaria de emergencia y su relación con la prevalencia de estrés. También identificó el vínculo entre cultura y clima organizacional, mostrando la influencia de la cultura sobre el clima organizacional.

Palavras chaves: cultura organizacional; Clima organizacional; Estrés; Urgencia y emergencia; Profesionales de la salud. 


\section{LISTA DE TABELAS}

Tabela 1 - Fatores, objetivos e questões da escala de clima organizacional ECO, Ribeirão Preto, SP, 2018.

Tabela 2 - Fatores, objetivos e questões da escala de clima organizacional ECO, Ribeirão Preto, SP, 2018.

Tabela 3: Caracterização dos profissionais da saúde participantes do estudo, segundo as variáveis sexo, idade, escolaridade, estado civil, Ribeirão Preto, SP, 2018.

Tabela 4: Caracterização dos profissionais da saúde participantes do estudo, segundo as variáveis relacionadas à profissão, Ribeirão Preto, SP, 2018.

Tabela 5: Setores de trabalho em agrupamento por complexidade dos profissionais da saúde participantes do estudo, Ribeirão Preto, SP, 2018.

Tabela 6: Cultura organizacional e a relação com o estresse atual nos profissionais do serviço de emergência, Ribeirão Preto, SP, 2018.

Tabela 7: Teste de associação entre Cultura organizacional e o estresse atual nos profissionais do serviço de emergência, Ribeirão Preto, SP, 2018.

Tabela 8: Clima organizacional e a relação com o estresse atual nos profissionais do serviço de emergência, Ribeirão Preto, SP, 2018.

Tabela 9: Teste de associação entre Clima organizacional e o estresse atual nos profissionais do serviço de emergência, Ribeirão Preto, SP, 2018.

Tabela 10: Associação do estresse entre variáveis sócio-demográficas e de trabalho, cultura e clima organizacional nos profissionais do serviço de emergência, Ribeirão Preto, SP, 2018 
Tabela 11: Correlação da cultura (IBACO) e clima (ECO) organizacional, Ribeirão Preto, SP, 2018.

Tabela 12: Variáveis preditoras do estresse, Ribeirão Preto, SP, 2018. 


\section{LISTA DE GRÁFICOS}

Gráfico 1: Comparativo entre as fases e os sintomas do estresse dos profissionais da saúde participantes do estudo, Ribeirão Preto, SP, 2018.

Gráfico 2: Média por fatores da cultura organizacional dos profissionais do serviço de emergência, Ribeirão Preto, SP, 2018.

Gráfico 3: Média por fatores do clima organizacional dos profissionais do serviço de emergência, Ribeirão Preto, SP, 2018. 


\section{LISTA DE QUADROS}

Quadro 1: Modelo proposto para este estudo. Ribeirão Preto, 2018 


\section{LISTA DE FIGURAS}

Figura 1: Cultura e clima organizacional e sua relação com o estresse entre profissionais de um serviço de emergência. Ribeirão Preto, 2018. 


\section{LISTA DE SIGLAS}

CFM - Conselho Federal de Medicina

BVS - Biblioteca Virtual em Saúde

Scielo - Scientific Electronic Library Online

GAS - General Adaptation Syndrome

RH - Recursos Humanos

H - Hipótese

DRS-13 - $13^{\text {a }}$ Direção Regional de Saúde do Estado de São Paulo

HCFMRP - Hospital das Clinicas da Faculdade de Medicina de Ribeirão Preto

USP - Universidade de São Paulo

UTI - Unidade de Terapia Intensiva

EERP - Escola de Enfermagem de Ribeirão Preto

ECO - Escala de Clima Organizacional

IBACO - Instrumento Brasileiro para Avaliação da Cultura Organizacional

ISSL - Inventário de Sintomas de Stress para adultos

TCLE - Termo de Consentimento Livre e Esclarecido

dp - Desvio padrão

CTI - Centro de Terapia Intensiva

UCO - Unidade Coronariana

MI - Moléstias Infecciosas

CCIH - Comissão de Controle de Infecção Hospitalar

P - Nível de significância

IC - Intervalo de confiança 


\section{SUMÁRIO}

Sumário

Página

1. INTRODUÇÃO 24

$\begin{array}{ll}1.1 \text { Apresentação } & 24\end{array}$

1.2 Revisão de literatura 25

1.2.1 Evolução e características dos serviços de emergência no Brasil;

1.2.2 Estresse em Profissionais de Emergência; 28

1.2.3 Cultura organizacional; $\quad 30$

1.2.4 Clima organizacional. $\quad 34$

2. JUSTIFICATIVA 40

3. OBJETIVOS 43

3.1 Geral; $\quad 43$

3.2 Específicos. 43

4. HIPÓTESES 45

5. MATERIAIS E MÉTODOS 47

5.1 Tipo do estudo; $\quad 47$

$\begin{array}{ll}5.2 \text { Período; } & 47\end{array}$

5.3 Local; $\quad 47$

5.4 População e Amostra; $\quad 48$

5.5 Critérios de seleção; 48

5.6 Proteção de participação do estudo; 49 
5.7 Coleta de dados;

5.8 Instrumentos de coleta de dados;

5.9 Procedimentos da coleta de dados;

5.10 Análise estatística;

5.11 Riscos e benefícios do estudo;

5.12 Aspectos éticos.

6. RESULTADOS 58

6.1 Caracterização dos Participantes; 58

6.2 Estresse atual entre os profissionais do serviço de emergência; 60

6.3 Cultura organizacional e a relação com o estresse atual nos profissionais do serviço de emergência;

6.4 Clima organizacional e a relação com o estresse atual nos profissionais do serviço de emergência;

6.5 Associação do estresse com variáveis sócio-demográficas e de trabalho, nos profissionais do serviço de emergência;

67

6.6 Correlação entre a cultura e o clima organizacional nos profissionais do serviço de emergência;

6.7 Variáveis preditoras do estresse atual relacionadas aos profissionais do serviço de emergência;

6.8 Síntese dos resultados mais importantes.

8. CONCLUSÕES FINAIS 80

9. REFERÊNCIAS 


\section{INTRODUÇÃO}

\subsection{Apresentação}

No mundo do trabalho há constantes transformações, principalmente, no que se refere aos temas como globalização, flexibilização, competitividade e novas formas de organização do trabalho. Essas transformações geram avanços científicos e tecnológicos, tornando-se um ambiente complexo (KREIN, 2013). Os avanços tecnológicos, sociocultural e as consequências da globalização geram benefícios ao mundo moderno, trazendo melhorias à saúde assim como de vida digna e decente para todos, porém não podemos deixar de identificar que a qualidade de vida dos trabalhadores estão sendo diretamente afetada por tais mudanças, tanto mudanças nas formas de organização do trabalho, como a regulação da relação de emprego, com o avanço da flexibilização, contribuem para criar um ambiente de trabalho não saudável, sendo assim, observa-se um crescimento significativo de profissionais adoecidos (DEJOURS, et. al., 1994; LORENZETTI, et. al., 2012; KREIN, 2013). Com isso, observa-se a necessidade de avançar nos estudos sobre o ambiente de trabalho.

Estudos evidenciam que o trabalho em saúde é uma atividade que exige mais atenção e desgaste emocional, relacionado ao contato constante com pessoas, ocupando grande parcela do tempo de cada indivíduo, comprometendo seu convívio em sociedade, nem sempre possibilitando sua realização profissional, podendo causar problemas desde a insatisfação até mesmo a exaustão dos profissionais (PORTELA, et. al., 2015; TAVARES, et. al., 2012; BANNAY, et. al., 2013; FERNANDES, et. al., 2012). No Brasil, a força de trabalho na saúde é mantida por 1,5 milhão de profissionais, registrados em conselhos profissionais (ALMEIDA FILHO, 2011). Diante disso, sabe-se que os profissionais de saúde estão vulneráveis ao estresse relacionado ao trabalho, uma vez que sua atividade profissional exige contato intenso com pessoas e enfrentamento de inúmeras situações de estresse (TRINDADE, et. al., 2010).

Um dos principais cenários apontados pela literatura científica como ambiente estressor são os serviços de emergência, devido ao trabalho normatizado, fragmentado, com excessiva responsabilidade, rotatividade de turnos e cobrança por constante ampliação de conhecimento. Os profissionais atuantes nos serviços de emergência deparam-se diariamente com situações que exigem condutas rápidas, conhecimento, autocontrole e eficiência ao prestarem assistência ao 
paciente, a fim de não cometerem erros (BEZERRA, et. al., 2012; AVELINO, et. al., 2013; TAVARES, et. al., 2012; FERNANDES, et. al., 2013). Na sociedade atual há diversos tipos de situações que exigem adaptações constantes de cada indivíduo, não apenas de forma a superá-las, mais também de suportar essas adaptações, que muitas vezes, causam angústia, sofrimento e até mesmo sintomas físicos, psíquicos, mentais e emocionais (OLIVEIRA, et. al., 2014).

Em decorrência desta angustia, o adoecimento vem por consequência ao estresse, sendo comum apresentarem alguns sintomas físicos (fadiga, dores de cabeça, insônia, alterações intestinais, tremores, dores pelo corpo, extremidades frias, palpitações, náuseas e resfriados), sintomas psíquicos, mentais e emocionais (como confusão, perda do senso de humor, depressão, diminuição da concentração e memória, ansiedade, indecisão, raiva, depressão, frustração, ansiedade, nervosismo, medo, preocupação, irritabilidade e impaciência) (MUROFUSE, et. al., 2005).

Diante disso, estudos sobre cultura e clima organizacional estão sendo desenvolvidos no mundo todo, visando entender a interferência cultural, política, administrativa e organizacional das instituições (WEI, et. al., 2014; SANTOS, et. al., 2013; SCHNEIDER, et. al., 2013). Porém, não são encontrados estudos sobre cultura e clima organizacional voltado aos trabalhadores de saúde em serviços de emrgência, principalmente os que se relacionam com a prevalência de estresse são mais escassos, dessa forma ressalta-se a importância de estudos sobre cultura e clima organizacional em serviços de saúde de emergência, visando identificação de possíveis implicações deste nas relações interpessoais entre os profissionais, bem como no desenvolvimento do estresse e suas consequências.

\subsection{Revisão de literatura}

\subsubsection{Evolucão e características dos servicos de emergência no Brasil}

No mundo o serviço de emergência se iniciou com as chamadas "Ambulâncias Voadoras" em 1795 para Napoleão na Prússia. Após longos anos evolui-se pouco sobre na área da emergência. Durante a Guerra Civil, observou-se o aumento de sobrevivência das vítimas quando iniciado o tratamento antes do paciente chegar ao hospital com profissionais não médicos. 
Somente em meados da década de 1960 que houveram avanços e capacitação de profissionais para o atendimento de emergências (MENDES, 1995).

Nos Estados Unidos profissionais atuantes nos serviços de emergências, possuem a responsabilidade de agir com decisões críticas e imediatas baseadas em conhecimentos e avaliações. Antes de atenderem aos pacientes, os profissionais já devem possuir o conhecimento e habilidade necessária para determinado tipo de atendimento, dessa forma a renovação do conhecimento se dá continuamente, tornando profissionais sempre atualizados quanto às inovações no mundo da saúde. (TACSI, et. al., 2004).

As emergências são caracterizadas pela necessidade de o paciente ser atendido em um curtíssimo espaço de tempo.

Segundo a Resolução do Conselho Federal de Medicina - CFM 145/95:

Define-se por URGÊNCIA a ocorrência imprevista de agravo à saúde com ou sem risco potencial de vida, cujo portador necessita vida, necessita de assistência médica imediata. Define-se por EMERGÊNCIA a constatação médica de condições de agravo à saúde que impliquem em risco iminente de vida ou sofrimento intenso, exigindo, portanto, tratamento médico imediato.

Segundo o Ministério da Saúde Brasileiro (2001) o serviço de emergência iniciou no Brasil, devido ao grande número de mortes por acidentes, envenenamento e violências podendo ser evitado através de um atendimento mais rápido. Devido à demanda de acidentes que aconteciam nas ruas em torno de 1983, o serviço de emergência iniciou-se no contexto histórico do Socorro Médico de Urgência (WEHBE, 2001; TACSI, et. al., 2004), porém só na década de 80 que foi melhorando a capacitação desses profissionais atuantes na área da emergência.

Em vista de melhorar a organização e atendimentos das emergências, criou-se o mecanismo de apoio à "Implantação dos Sistemas Estaduais de Referência Hospitalar para o Atendimento de Urgência e Emergência", com o objetivo de estimular, apoiar e organizar o sistema de referência hospitalar (BRASIL 2001).

Segundo BRASIL (2002), com o crescimento do número de acidentes e da violência urbana e a insuficiente estruturação da rede assistencial, também identificou-se a necessidade de aprofundar o Sistema de emergência, aperfeiçoando as normas já existentes e expandir o 
atendimento pré-hospitalar móvel e de transporte inter-hospitalar. Neste sentido criou-se o Regulamento Técnico dos Sistemas Estaduais de Emergência, que estabelece:

“[...] os princípios e diretrizes dos Sistemas Estaduais de Urgência e Emergência, as normas e critérios de funcionamento, classificação e cadastramento de serviços e envolve temas como a elaboração dos Planos Estaduais de Atendimento às Urgências e Emergências, Regulação Médica das Urgências e Emergências, atendimento préhospitalar, atendimento pré-hospitalar móvel, atendimento hospitalar, transporte Interhospitalar e ainda a criação de Núcleos de Educação em Urgências e proposição de grades curriculares para capacitação de recursos humanos da área.” (BRASIL, 2002).

Os profissionais que atuam na área de emergência lidam constantemente com diversas variações, como por exemplo, atuar em uma área que não coincide sempre com a área de profissionalização ou até de sua formação específica (HETTI, et. al., 2013).

As organizações hospitalares no Brasil têm rotinas complexas e com elevada demanda, visto das necessidades dos pacientes comparados a outras unidades de saúde consideradas de menor complexidade. Sabe que os hospitais têm como princípio a assistência ao paciente de alta complexidade, promoção da saúde, prolongamento da vida e até o acompanhamento na morte (ALVES, et. al., 2006).

As características dos serviços de emergência são de dominação, controle, superlotação, ritmo acelerado, e sobrecarga de trabalho para os profissionais da saúde. No processo do trabalho a organização se faz com a divisão rígida de tarefas e desvalorização dos conhecimentos e das vivências dos trabalhadores, causando como consequência desresponsabilização pelo atendimento (MARQUES, et. al., 2008).

Os atendimentos nesse tipo de serviço sujeitam os profissionais à carga horária excessiva, plantões noturnos, exposição à radiação e outros tipos de produtos químicos e também a lidar com sofrimento e dor constantes de pacientes e familiares (ALVES, et. al., 2006).

Os profissionais da saúde trabalham com autonomia relativa, sendo na maioria das vezes modeladas e orientadas através da figura de um médico ou por gestores em instituições verticalizadas. Essa atuação manual e repetitiva faz com que o cuidado ao paciente seja vazio de conteúdo científico que ao longo do tempo aliena o trabalhador. Mesmo nos locais mais enrijecidos, onde a autonomia dos profissionais é escassa, há possibilidades de mudanças para 
que seja questionada a lógica estruturada de produção de cuidados. Podendo assim, o profissional atuar com mais autonomia dentro de seus limites, tornando um cuidado mais crítico ao paciente (MARQUES, et. al., 2008). Além disso, os profissionais da saúde lidam com o fato de cuidar de

pessoas doentes, o que pode gerar angústia e sofrimento para os mesmos, aumentando assim o seu nível de estresse (ALMEIDA, et. al., 2014).

Diante disso, pensar sobre a constituição e organização do trabalho é de grande importância para que dessa forma possamos caracterizar o tipo de cultura e clima organizacional presentes no local e com isso relacionar com a possibilidade do profissional ter ou não estresse, e caso ele tenha, investigar em qual nível ele se encontra e relacionar com o tipo de organização.

Tendo em vista a importância da caracterização da organização, a fim de compreender a relação saúde-organização-profissional-trabalho, se torna essencial entender através da cultura e clima organizacional como isso se faz, visto que em uma revisão na literatura, utilizando as bases de dados PubMed, BVS e Scielo, os trabalhos sobre clima e cultura organizacional em profissionais da saúde em serviços de emergência são escassos (DAL PAI, et. al., 2008).

Deste modo, constata-se que estudos nestes serviços e com as equipes que neles atuam podem contribuir para melhor organização, maior qualificação da assistência e promoção da saúde destes trabalhadores.

\subsubsection{Estresse em Profissionais de Emergência}

O termo "stress" (em português estresse) deriva-se do latim "stringere". O termo stress foi utilizado no campo da Física, referindo-se a uma força extrema, pressão ou tensão que era submetida a objetos ou pessoas por Robert Hooke. Foi apenas a partir do século XX que o termo estresse passou a ser utilizado na área da saúde (CHROUSOS, et. al. 1988; CHROUSOS, et. al. 1992; GUILLÉN GESTOSO, 2005).

O estresse é um tema amplamente estudado. Ele permeia a vida do homem há muito tempo e com o passar do tempo várias abordagens foram surgindo. Hans Selye é considerado o primeiro estudioso do estresse em sua dimensão biológica, considerando-o um componente intrínseco a toda doença, produzindo modificações na composição química e na estrutura do corpo (SELYE, 1936). Assim, Selye desenvolveu um modelo designado Síndrome Geral de Adaptação (General Adaptation Syndrome - GAS), que compreende a dilatação do córtex da 
suprarrenal, atrofia dos órgãos linfáticos e úlceras gastrointestinais, além de perda de peso e outras alterações (SELYE, 1936).

A GAS constitui um conjunto de reações inespecíficas e gerais do organismo contra estímulos persistentes causadores de estresse e divide as manifestações e alterações produzidas pelo sistema biológico em consequência ao estresse em três fases. A primeira fase de alarme ou alerta é caracterizada por manifestações agudas nas quais o organismo identifica o estressor e mobiliza uma resposta orgânica rápida para o enfrentamento. Na segunda fase de resistência, quando as manifestações agudas desaparecem, o organismo resiste independente da permanência ou não do estressor, fazendo com que o organismo se adapte. Por fim na terceira fase de exaustão, quando há a volta das reações da primeira fase e pode haver o colapso do organismo, o fator estressor permanece e o organismo passa a não ser capaz de eliminá-lo ou adaptar-se novamente (SELYE, 1936; MINOZZO, et. al., 2008; SOUSA, et. al., 2015).

Selye afirma, o estresse pode ser identificado em qualquer fase, não é necessário perpetuar pelas três fases para haver o registro da síndrome, somente o estresse em sua fase mais grave, leva à exaustão e à morte (FARO, et. al., 2013; SELYE, 1936).

Lipp (1994), acrescentou a este modelo uma quarta fase denominada "quase exaustão", entre as fases de resistência e exaustão. Segundo a autora nesta fase há enfraquecimento e incapacidade do indivíduo em resistir ou adaptar-se ao estressor (LIPP, et. al., 1994).

É cada vez mais crescente o número de pesquisas científicas sobre o estresse. Esse crescimento sobre a temática deu-se ao fato de $90 \%$ da população mundial estar sendo afetada pelo estresse, segundo dados da Organização Mundial de Saúde, tomando uma verdadeira epidemia global (BATISTA, et. al., 2006; OMS, 2016).

Sabe-se que o estresse é um fenômeno que faz parte da vida do ser humano, seja no âmbito pessoal, social ou profissional. Estudos apontam que profissionais estressados têm o seu desempenho diminuído e dessa forma eleva os problemas de saúde dos mesmos.

No mundo do trabalho, devido à demanda, o estresse pode estar relacionado a respostas emocionais, físicas e ameaçadoras. Sabe-se que nos serviços de emergência as funções da equipe são mais independentes, interdependentes e/ou de colaboração, assim se faz necessário que a equipe trabalhe bem em conjunto e conheça as limitações legais e atribuições de acordo com sua função, pois caso o trabalho seja desarticulado o cliente poderá vir a ter sérios riscos à saúde. 
O trabalho na área da saúde é de grande responsabilidade, pois o profissional precisa estar preparado e sempre atualizado para lidar com as diversas situações que ocorrem em seu dia-a-dia. Sabe-se que nesse ramo de trabalho o estresse "caminha" próximo a esses profissionais, devido à responsabilidade de lidar com a vida alheia, nas unidades de emergência esses profissionais estão ainda mais susceptíveis ao estresse (CANDEIAS et. al., 1992).

Em serviços de emergência, alguns autores apontam como alguns dos problemas vivenciados pelos profissionais os sinais de esgotamento, cansaço, frustração no seu cotidiano de trabalho e síndrome de Burnout (BENTLEY, et. al., 2013; GHERARDI-DONATO, et. al., 2015; ADRIAENSSENS, et. al., 2015).

Em uma Revisão na literatura, foi evidenciado que profissionais da saúde estão sujeitos ao impacto do estresse, devido ao cuidado direto e prolongado com o paciente, situações de emergência, sentimento de dor e sofrimento junto ao paciente e familiares (MELO, et. al., 2013).

Estudos evidenciaram que estes profissionais da saúde estão sujeitos ao estresse ocupacional que pode estar relacionado a condições de trabalho, escassez de recursos, carga horária de trabalho, plantões, relacionamentos interpessoais, competitividade, etc. $\mathrm{O}$ que, muitas vezes, pode estar relacionado a absenteísmo e ao adoecimento destes profissionais (BEZERRA, et. al., 2012; DUFFY, et. al., 2015; ADRIAENSSENS, et. al., 2015; GHERARDI-DONATO et. al., 2015).

Entre os profissionais da saúde que atuam em serviços de emergência, os eventos estressores mais referidos são: a escassez de recursos humanos, recursos materiais e instalações físicas inadequadas, carga horária de trabalho, plantões noturnos, interface trabalho/lar, relacionamentos interpessoais, trabalhar em clima de competitividade e distanciamento entre teoria e prática (BEZERRA, et. al., 2012; HAPPELL, et. al. 2013; DUFFY, et. al. 2015; ADRIAENSSENS, et. al. 2015; GHERARDI-DONATO, et. al., 2015).

Neste sentido, o presente estudo tem como objetivo principal identificar a influência do clima e cultura organizacional para a ocorrência de estresse em profissionais de saúde que atuam em serviços de emergência.

\section{$\underline{1.2 .3 \text { Cultura organizacional }}$}


A palavra cultura tem um sentido muito amplo, as vivências humanas transmitidas de uma geração para outra (PASCHINI, 2006). Em latim a palavra cultura é escrita colere, significando cultivar, inicialmente essa palavra teve como sentido cultivar o solo, após tornou-se também o sentido de cuidar de crianças, no significado de acompanhar o desenvolvimento físico, intelectual e moral da criança (PIRES, et. al. 2006).

O termo cultura organizacional teve seu início nas teorias administrativas, os estudos referente a essa temática iniciaram no final do século XVIII e início do século XIX. Estudos na empresa Western Electric Company fizeram com que inicia-se a conceituação de cultura para o âmbito das organizações (TRICE et. al., 1993), caracterizando a cultura para as crenças da sociedade tribal, estrutura social e os valores nas interações humanas.

Em 1951, no livro de Elliot Jacques “The changing culture of a factory” (JACQUES, 1951), o autor descreveu as mudanças organizacionais da empresa metalúrgica inglesa e também apresentou as relações entre cultura, personalidade e estrutura organizacional (JACQUES, 1951).

Na década de 1970 o termo cultura foi incorporado na literatura através das expressões "cultura corporativa" ou "cultura organizacional", por Pettigrew (1979), definindo cultura como "um sistema de significados público e coletivamente aceitos por um dado grupo, em um certo período de tempo. Esse sistema de termos, formas, categorias e imagens interpretam para as pessoas as suas próprias situações”. (PETTIGREW, 1979 p. 574).

Na década de 1980, os estudos sobre cultura organizacional ganharam força nas empresas multinacionais devido à mudança de poder e na sociedade industrial e pós-industrial (PIRES, et. al. 2006; SANTOS, et. al., 2010; BENDASSOLLI, et. al., 2015). A temática continuou em evidência na década de 1990, devido à globalização dos mercados e as mudanças nas organizações, provocadas pelas fusões e aquisições, novas tecnologia, estabilidade, novos conceitos de trabalho (KREIN, 2013; BARROS, 2003).

O termo Cultura Organizacional é definido de diversos modos, dependendo da linha de pesquisa do autor, porém é possível encontrar consenso na literatura de elementos constituintes da cultura organizacional, tais quais: Valores; Crenças ou pressupostos; Ritos, rituais e cerimônias; Estórias e mitos; Tabus; Heróis; Normas; Processo de comunicação (FREITAS, 2007).

$\mathrm{Na}$ literatura, são identificadas cinco tendências sobre cultura organizacional, são compreendidos como "variável da organização" (organizações possuem cultura) ou 
"organizações concebidas como expressões culturais" (organizações são culturas). Essas cinco tendências, são:

Administração comparativa ou transcultural: tem como objetivo conhecer a cultura e estrutura local ou nacional e a influencia exercida sobre a cultura organizacional. Para realizar esse tipo de analise é feito uma comparação entre trabalhadores de países ou regiões diferentes, porém com o mesmo tipo de organização. Segue-se a linha de raciocínio que a cultura é incorporada na organização através de seus membros e passada através das ações e padrões de atitudes (SMIRCICH, 1983).

Cultura corporativa: Essa tendência segue o princípio que a organização é produtora de cultura, elementos culturais, como os rituais, lendas e cerimônias. Essa linha também segue a teoria de Sistemas, com o seguimento que a cultura auxilia no equilíbrio sistémico geral e a efetividade organizacional (SMIRCICH, 1983).

Cognição organizacional: Essa concepção tem como objetivo o entendimento das regras que regem os grupos sociais, a visão de mundo dos seus participantes e as intervenções organizacionais. Nessa linha a cultura é um conhecimento compartilhado ou um sistema de conhecimentos e crenças (SMIRCICH, 1983).

Simbolismo organizacional: Essa tendência decodifica ou interpretar os significados dos discursos simbólicos dos participantes da organização. Esse ponto tem como base o ponto de vista dos informantes (como são interpretados e compreendidos as experiências e como relacionam-se as suas ações) (SMIRCICH, 1983).

Processos inconscientes e organizações: Nessa linha o principio é tratar a cultura como uma manifestação e expressão de operações inconsciente da mente.

São diversos os autores, considerados importantes, na literatura internacional que estudam cultura organizacional, entre eles destaca-se: Geert Hofstede; Richard Pascale e Anthony Athos; Edgar Henry Schein; Joanne Martins; Linda Smircich; Mats Alvesson; John Van Maanen.

Hofstede (1997) aborda as influências da cultura nacional na cultura organizacional, salientando que cultura organizacional é como o resultado de uma dinâmica cultural maior na sociedade em que esta organização se insere. Os estudos realizados por Hofstede (1997) evidenciam o conceito de manifestação de cultura, classificados em valores, rituais, heróis e símbolos. 
Schein (1992) define cultura como um padrão de suposições básicas compartilhadas, aprendidas por um determinado grupo, após a compreensão e entendimento adequado, que são transmitidos aos novos membros como modelo correto e único de pensar e sentir. A cultura pode ser transmitida, mudada e aprendida (SCHEIN, 2007).

Smircich (1983) trabalho nos estudos que versam sobre cultura organizacional, relacionando cinco paradigmas representativos das pesquisas antropológicas, sendo eles, funcionalismo de Malinowski (cultura é um instrumento a serviço das necessidades biológicas e psicológicas humanas), funcionalismo-estrutural (cultura é um mecanismo adaptativo regulador), Etnociência (cultura é vista como um sistema de cognições compartilhadas), Antropologia Simbólica (cultura é tida como sistema de símbolos compartilhados), e Estruturalismo de LéviStrauss (cultura é uma projeção da infraestrutura universal da mente, são os processos inconscientes).

Alvesson (1993) aponta a cultura organizacional como uma forma de pensar a realidade social não dependendo de nenhum objeto empírico determinado.

No Brasil, também há diversos autores, destaca-se: Maria Tereza Leme Fleury; Maria Ester de Freitas; Narbal Silva; José Carlos Zanelli; Suzana da Rosa Tolfo; Marco Antonio Oliveira; Álvaro Tamayo; Juliana Barreiro Porto; Lívia de Oliveira Borges; Maria Cristina Ferreira; Eveline Maria Leal.

Fleury e Fischer (1989), afirma que:

\footnotetext{
"a cultura é concebida como um conjunto de valores e pressupostos básicos expresso em elementos simbólicos, que em sua capacidade de ordenar, atribuir significações, construir a identidade organizacional, tanto age como elemento de comunicação e consenso, como oculta e instrumentaliza as relações de dominação".
}

Segundo Pickina (2008) cultura organizacional é um fenômeno de natureza psicossocial complexo e multifacetado. Na literatura algumas variáveis para definir cultura organizacional são comuns, tais como: valores; crenças ou pressupostos; ritos, rituais e cerimônias; histórias e mitos; tabus; heróis; normas e processos de comunicação (SANTOS, et. al., 2014; PAZ, et. al., 2014; PICKINA, 2008; PIRES, et. al., 2006 ). 
As principais funções da cultura organizacional são integrar os trabalhadores para que saibam como se relacionar, ajudar na adaptação com o meio externo e como reduzir a ansiedade de gestores e outros trabalhadores. Entende-se cultura, de uma forma simplificada, em 3 partes, a parte superficial - Exocultura (formada por condutas experimentais e símbolo em processo de assimilação), a parte intermediária - Mesocultura (considerada por padrões e hábitos razoavelmente estabelecidos), por fim a parte mais profunda - Endocultura (caracterizada pelo núcleo duro/ enrijecido já estabelecido) (SCHEIN, 2009; ETKIN, 2005).

Diante do exposto, justifica-se a importância do tema, sabendo que as pessoas têm suas metas individuais e sua ética. $\mathrm{O}$ assunto é de grande relevância para o meio científico e ao mesmo tempo uma preocupação no desenvolvimento da pesquisa, para identificar e reconhecer a tendência na literatura analisada.

A cultura organizacional é de suma importância para a identificação das culturas rígidas dentro das instituições, para um bom desenvolvimento interpessoal. Avaliar a cultura organizacional é importante, pois ela pode afetar positiva e negativamente o comportamento das pessoas e o modo como à instituição é organizada.

\subsubsection{Clima organizacional}

O conceito de clima, inicialmente tem origem na meteorologia. A palavra clima deriva-se do grego klima e significa inclinação ou atmosfera. Desde o final da década de 1920, estudos foram iniciados sobre o clima organizacional nas empresas, por Elton Mayo em uma fábrica de Chicago. Tais estudos puderam identificar que as mudanças físicas, sociais e do ambiente de trabalho podem alterar percepções, sentimentos, atitudes e comportamentos dos trabalhadores, como fadiga, acidente de trabalho, redução no desempenho e produtividade (LITWIN, et. al. 1968, ASHKANASY, et. al., 2000).

O aumento na utilização de instrumentos que avaliam o clima nas organizações tem sido atribuído à abrangência teórica do construto, juntamente com a capacidade de avaliar os

fenômenos psicossociais complexos (liderança, interações humanas, reconhecimento, entre outras). É uma variável que influi na qualidade, produtividade e rentabilidade das organizações (SILVA, 2003). 
Ainda há confusão entre clima organizacional e clima psicológico, muitas vezes sendo tratados como sinônimos. Após muitos estudos, entende-se que clima organizacional são elementos cognitivos, enquanto clima psicológico são elementos afetivos. Alguns autores distinguem os termos, conceituando clima psicológico como o significado da ligação individual no contexto de trabalho e clima organizacional como percepções ligadas a um aspecto particular do trabalho, partilhadas pelos trabalhadores (SCHNEIDER, et. al., 1983; KINPARA, et. al., 2014; LIMA, et. al., 2015)

Segundo Forehand e Gilmer (1964), clima organizacional é como um conjunto de características que: a) distinguem a organização de outras organizações; b) são relativamente duradouras ao longo do tempo; e c) influenciam os comportamentos dos trabalhadores na organização.

Para Payne e Mansfield (1973), o clima organizacional é considerado como o elo conceitual de ligação entre o nível individual e o nível organizacional, no sentido de expressar a compatibilidade ou congruência das expectativas, valores e interesses individuais com as necessidades, valores e diretrizes formais.

Segundo Coda (1993), clima organizacional é o indicador do grau de satisfação dos membros de uma empresa, em relação a diferentes aspectos da cultura ou realidade aparente da organização, tais como: política de RH, modelo de gestão, missão da empresa, processo de comunicação, valorização profissional e identificação com a empresa.

Chiavenato (2004) define clima organizacional como:

"O clima organizacional constitui o meio interno ou a atmosfera psicológica característica de cada organização. O clima organizacional está ligado ao moral e à satisfação das necessidades dos participantes e pode ser saudável ou doentio, pode ser quente ou frio, negativo ou positivo, satisfatório ou insatisfatório, dependendo de como os participantes se sentem em relação à organização. $\mathrm{O}$ conceito de clima organizacional envolve fatores estruturais, como tipo de organização, tecnologia utilizada, política da companhia, metas operacionais, regulamentos internos, além de atitudes e comportamentos internos, além de atitudes e comportamentos sociais que são encorajados ou sancionados através dos fatores sociais" (CHIAVENATO, 2004). 
Alguns métodos para avaliar o clima organizacional foram validados há alguns anos, os estudos sobre o tema centram-se em setores administrativos e empresariais, sendo escassos estudos com profissionais de saúde (MARTINS, et. al., 2004; MANÉ, et. al., 2014; PUENTEPALACIOS, et. al., 2013; SANTOS, et. al., 2013).

Os primeiros estudos sobre clima organizacional ocorreram nos Estados Unidos, no início de 1960, com os trabalhos de Forehand e Gilmer (1964) sobre comportamento organizacional, dentro de um grande movimento da administração chamado de Comportamentalismo e influenciaram o estabelecimento de alguns conceitos e indicadores importantes sobre clima organizacional (RIZZATTI, 2002).

Com base nos estudos de Forehand e Gilmer (1964), os pesquisadores Forehand e Gilmer (1964) realizaram experiências em três diferentes organizações americanas e obtiveram resultados que apresentavam três situações diferentes em termos de satisfação e desempenho no trabalho: revelaram relações com os motivos de realizações, afiliação e poder.

Modelo de Litwin e Stringer (1968) utiliza um questionário baseado em nove fatores/indicadores (estrutura, responsabilidade, desafio, recompensa, relacionamento, cooperação, conflitos, identidade, padrões). Este modelo foi o primeiro a ser testado em empresas de grande porte, os resultados apresentaram distintos climas organizacionais em empresas que tinham diferentes políticas para seus Recursos Humanos e comprovou a importância dos estudos sobre o clima organizacional nas empresas.

Alguns outros modelos para avaliação do clima organizacional foram surgindo no decorrer dos anos, entre eles pode se destacar: o Modelo Kolb (1986), o Modelo de Souza (1977, 1978, 1980, 1982, 1983), o Modelo de Sbragia (1983), o Modelo de Rizzatti (2002) e o Modelo de Menezes (2009).

O Modelo de Kolb et. al. (1986) utiliza uma escala de sete fatores/indicadores. Além da responsabilidade, padrões e recompensas, citados no modelo anterior, acrescenta-se neste modelo o conformismo, clareza organizacional, calor e apoio, liderança. Este modelo surgiu duas décadas depois de Litwin e Stringer (1968), também nos Estados Unidos, após estudos para tentar aperfeiçoar o modelo de Litwin e Stringer.

No Brasil, Souza $(1977,1978,1980,1982,1983)$ difundiu e aplicou as pesquisas sobre clima organizacional, seguindo o modelo adaptado de Litwin e Stringer. 
O Modelo de Sbragia (1983) utiliza uma escala de vinte fatores/indicadores. Além de conformidade, estrutura, recompensas, cooperação, padrões, conflitos e identidade, há também, estado de tensão, ênfase na participação, proximidade da supervisão, consideração humana, autonomia presente, prestígio obtido, tolerância existente, clareza percebida, justiça predominante, condições de progresso, apoio logístico proporcionado, reconhecimento proporcionado, forma de controle. Este modelo baseou-se ainda no modelo de Litwin e Stringer, a partir de um amplo estudo realizado em 13 instituições públicas de pesquisa no Brasil, na década de 1980. Este modelo é mais abrangente que os anteriores, porém demonstrou várias deficiências institucionais relacionadas com a política e estratégia de seus Recursos Humanos, não só nas empresas pesquisadas, mas com reflexos em outras empresas do setor público e em empresas do setor privado no Brasil.

O modelo de Rizzatti (2002) avalia o clima organizacional nas universidades federais do sul do Brasil e forneceu dados importantes para a reavaliação e reestruturação de diversos aspectos organizacionais como: políticas e estratégias de recursos humanos, política de assistência e benefícios, estrutura organizacional, tecnologias educacionais, estilos de liderança, capacitação profissional, planejamento institucional, processo decisório, comunicação, conflitos de interesse, avaliação institucional, qualidade do ensino, autonomia universitária, etc. Segundo Rizzatti (2002) o modelo é adequado para avaliar o clima organizacional em universidades federais, mas não pode ser aplicado genericamente em qualquer tipo de empresa.

Rodrigues (2016) destaca que o clima organizacional é de suma importância para o bom desenvolvimento interpessoal de uma instituição, no qual conseguimos avaliar a qualidade do ambiente psicológico da mesma, em decorrência do estado motivacional das pessoas.

Uma pesquisa de clima organizacional em serviços de saúde no Brasil é uma proposta com grandes benefícios para esses serviços, podendo fornecer à instituição: uma visão ampla do ambiente em que se encontra seu serviço, qual a visão dos funcionários, a realização pessoal dos mesmos, satisfação em trabalho na empresa, se suas necessidades tanto fisiológicas quanto a realização pessoal e como estão sendo atendidas essas necessidades.

Avaliar o clima organizacional é importante, pois ele pode afetar positiva e negativamente o comportamento das pessoas, pode ser decisivo na capacidade da organização em atrair e reter talentos; podendo ser modificado; indicando satisfação dos membros da empresa em relação a 
diferentes aspectos da cultura ou realidade aparente da organização; apontando tanto origens de problemas já constatados, quanto o surgimento de problemas potenciais; 
2. JUSTIFICATIVA 


\section{JUSTIFICATIVA}

A relevância de estudos que abordem as temáticas cultura e clima organizacional, centrase no fato de que os fenômenos se completam, pois o clima organizacional identifica o grau de satisfação do membro de uma empresa, já a cultura organizacional identifica as crenças, valores, ritos, mitos, normas e processos de comunicação. O que evidencia a percepção de que o clima organizacional é fortemente influenciado pela cultura da organização.

Por outro lado, sabe-se que o estresse pode ocasionar graves consequências, principalmente entre profissionais da saúde, embora estudos sobre o tema sejam numerosos, sua ocorrência ainda carece ser avaliada em estudos ampliados que contemplem sua complexidade de maneira mais abrangente, considerando fatores pessoas, ambientais e psicossociais. Estima-se que o estresse afete mais de $90 \%$ da população mundial e que, por não ser uma doença em si, é subestimado, tendo como consequência a ausência de tratamentos e prevenção ao adoecimento (BEZERRA, et. al., 2012; OMS, 2016). Um levantamento da International Stress Management Association (Associação Internacional do Controle do Estresse) aponta o Brasil como o segundo país do mundo com o maior nível de estresse, com 30\% da população economicamente ativa com algum estado de estresse causado por pressão excessiva, atrás somente do Japão que apresenta 70\% de prevalência (SILVEIRA, 2010).

Diante o exposto, infere-se que questões relacionadas ao ambiente laboral, como clima e cultura organizacional e estresse podem estar relacionadas. Além disso, na literatura científica estudos sobre Clima e Cultura organizacional voltado para profissionais da saúde são escassos, em geral os estudos nessa temática são voltados a setores administrativos e acadêmicos. Neste sentido o presente estudo visa avaliar tais fenômenos em um serviço de saúde, na especialidade do setor de emergência, por ser este um setor de suma relevância na rede de serviços e por não ter sido encontrado na literatura científica estudos que abordem estes fenômenos conjuntamente.

Deste modo, este projeto teve por finalidade ampliar a compreensão sobre o clima e cultura organizacional no contexto do cuidado em serviços de emergência e seu impacto na ocorrência do estresse entre profissionais de saúde. Pretende-se realizar ampla divulgação e

discussão dos resultados em eventos científicos, contribuindo assim para reflexão e desenvolvimento de formas de prevenção de agravos à saúde desta clientela. 
Trata-se de uma proposta condizente com a atualidade, o cuidado na linha de emergência, notadamente em relação à saúde dos trabalhadores desta área.

De acordo com este contexto, o modelo teórico para ter ou não estresse atual, considerando as variáveis mediadoras do processo neste estudo, se apresenta da seguinte forma:

Quadro 1: Modelo proposto para este estudo. Ribeirão Preto, 2018

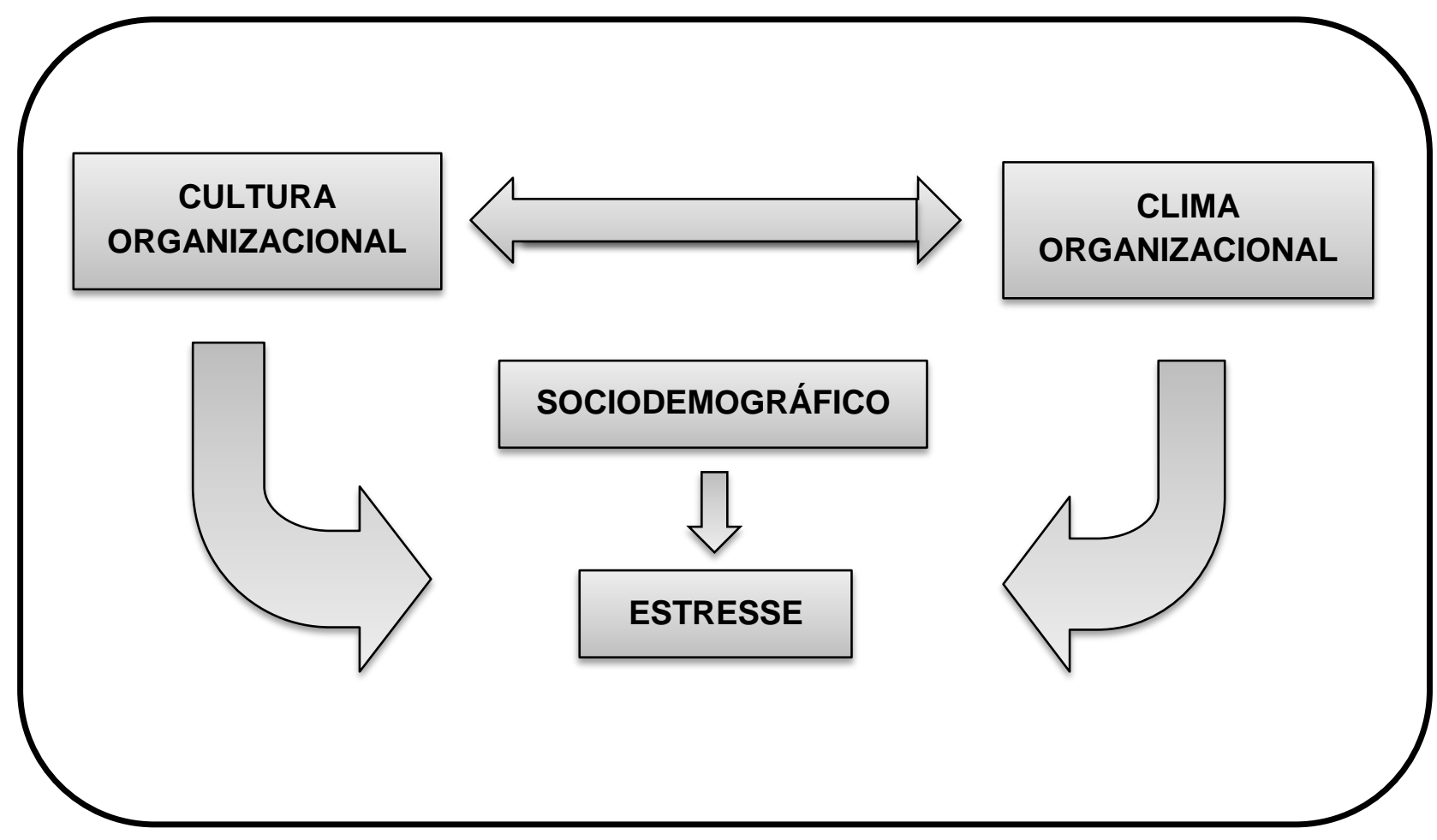

Fonte: Autor, 2018 


\section{OBJETIVOS:}

\subsection{Geral}

Identificar o clima e a cultura organizacional de uma organização de saúde em um serviço hospitalar de emergência e sua relação com a prevalência de estresse.

\subsection{Específicos}

- Definir as características sócio-demográficas e de trabalho dos profissionais;

- Caracterizar a ocorrência de estresse entre os profissionais do serviço de emergência;

- Caracterizar a Cultura Organizacional entre os profissionais do serviço de emergência;

- Caracterizar o Clima Organizacional entre os profissionais do serviço de emergência;

- Testar a associação entre características sócio-demográficas e de trabalho com a prevalência de estresse entre os profissionais;

- Testar a associação entre cultura organizacional e a prevalência de estresse entre os profissionais;

- Testar a associação entre clima organizacional e a prevalência de estresse entre os profissionais;

- Testar a correlação entre cultura e clima organizacional;

- Avaliar a cultura, o clima e variais sócio-demograficas como preditoras do estresse entre os profissionais. 
4. HIPÓTESES 


\section{HIPÓTESES}

\section{HO (nula)}

Não há relação entre clima, cultura organizacional e estresse atual em profissionais de saúde de serviços de emergência.

\section{H1}

Quanto maior o grau em que o valor ou prática da cultura organizacional mensurada pelo fator está presente na organização, maior será a ocorrência de estresse atual em profissionais de saúde de serviço de emergência;

\section{H2}

Quanto maior o grau em que o valor ou prática do clima organizacional mensurada pelo fator está presente na organização, maior será a ocorrência de estresse atual em profissionais de saúde de serviço de emergência; 


\section{MATERIAIS E MÉTODOS:}

\subsection{Tipo do estudo}

Foi desenvolvido um estudo transversal, analítico, exploratório, de abordagem quantitativa, dados coletados diretamente no local (campo) em que se deram ou surgiram os

fenômenos. Nesta pesquisa quantitativa objetivou-se apropriar da análise estatística para o tratamento dos dados. Sendo esta utilizada quando é exigido um estudo exploratório para um conhecimento mais profundo do problema, ou objeto de pesquisa. As pesquisas quantitativas são mais adequadas para apurar opiniões e atitudes explícitas e conscientes dos entrevistados, pois utilizam instrumentos padronizados. São utilizadas quando se sabe exatamente o que deve ser perguntado para atingir os objetivos da pesquisa. Elas testam, de forma precisa, as hipóteses levantadas para a pesquisa e fornecem índices que podem ser comparados com outros (GIL, 2002; BORDALO, 2006; LIMA-COSTA, et. al., 2003; PIOVESAN, et. al., 1995; DENZIN, et. al., 2005; NEVES, 1996; HAYATI, et. al., 2006; BARROS, et. al., 1990; FIGUEIREDO, 2004).

\subsection{Período}

O estudo foi realizado no período de janeiro de 2016 a outubro de 2018.

\subsection{Local}

Esse trabalho foi realizado em um serviço público de emergência de Ribeirão Preto/SP que possui 605.114 habitantes e em termos de saúde, é considerada o polo da $13^{\text {a }}$ Direção Regional de Saúde do Estado de São Paulo (DRS-13), sendo referência para as outras 25 cidades da região, num total de 1.349.170 habitantes (IBGE, 2012).

- A Unidade de Emergência do HCFMRP/USP é um hospital de referência terciária de toda DRS-13 para casos de emergência traumática e não traumática. Possui 180 leitos, 6 salas cirúrgicas, 18 leitos de UTI de adulto e 8 leitos de UTI pediátrica, havendo médicos de todas as especialidades em regime de plantão 24 horas por dia nos 7 dias da semana. 
Atende cerca de 42 mil casos, por ano, e realiza mais de 4500 cirurgias. Os profissionais de saúde serão: enfermeiros, técnicos de enfermagem, auxiliares de enfermagem e médicos. Uma particularidade dessa Unidade de Saúde é a alta rotatividade dos profissionais.

\subsection{População e Amostra}

De acordo com informações do setor de recursos humanos do local do estudo, a população total de médicos, enfermeiros, técnicos e auxiliares de enfermagem corresponde a 647 profissionais. A amostra do estudo foi obtida aplicando-se a fórmula usual proposta por Silva (2001), $\mathbf{N}=\mathbf{Z}^{\mathbf{2}}$.p.q / $\mathbf{E}^{\mathbf{2}}$, na qual:

Z: é o valor da curva normal correspondente ao nível de confiança

p: é a prevalência

$\mathrm{q}=1-\mathrm{p}$

E: é o erro máximo que se está disposto a cometer.

Assim, o número de participantes da amostra deveria ser no mínimo de 107. Foram convidados 212 profissionais a participarem do estudo e destes 155 aceitaram. Foram convidados profissionais de todos os setores Unidade de Emergência: Queimados, Centro de Terapia Intensiva Adulto, Centro de Terapia Intensiva Pediátrico, Sala de Urgência, Bloco Cirúrgico, Enfermaria Pediátrica, Moléstia Infecciosa Pediátrica, Unidade Coronariana, Neurologia, Unidade Respiratória, Clínica Cirúrgica, Central de Material, Descontaminação, Psiquiatria, Centro Cirúrgico, Banco de Sangue, Imagens - TMO, Clínica Médica, Hemodiálise, Comissão de Controle de Infecção Hospitalar.

\subsection{Critérios de seleção}

Tendo em vista os objetivos da pesquisa, foram incluídos na amostra aqueles profissionais enfermeiros, técnicos de enfermagem, auxiliares de enfermagem e médicos, que aceitaram participar do estudo e enquadrarem-se nos seguintes critérios de inclusão: profissionais de saúde atuantes no serviço há pelo menos um ano; que não estejam em férias ou afastamento. 
Esses critérios de seleção justificam-se ao fato que: a maior parte dos profissionais que atuam na área hospitalar, são enfermeiros, técnicos de enfermagem, auxiliares de enfermagem e médicos, são os profissionais que permanecem em contato direto e prolongado ao paciente. A maioria dos estudos sobre saúde são voltados para essa população.

\subsection{Proteção de participação do estudo}

Considerando os aspectos éticos referentes à pesquisa envolvendo seres humanos (Resolução 466/2012), o presente estudo após autorização do local de estudo foi submetido à avaliação do Comitê de Ética e Pesquisa da EERP. Foi assegurado aos participantes que as informações obtidas impossibilitem a identificação dos mesmos. Todos os participantes do estudo foram devidamente esclarecidos sobre a pesquisa, os seus direitos e os cuidados a eles garantidos. Após concordarem em participar, assinaram o Termo de Consentimento Livre e Esclarecido, em duas vias assinadas também pelo pesquisador, sendo uma via do pesquisador e a outra via do participante (BRASIL, 2012).

\subsection{Coleta de dados}

Foi realizada pelos pesquisadores da equipe deste projeto, devidamente treinados para tanto, de forma individual com cada participante, no próprio ambiente laboral. Foi acordado com a equipe gestora do hospital que o questionário sobre clima, cultura e estresse fossem respondidos fora do local de trabalho.

\subsection{Instrumentos de coleta de dados}

Para a obtenção dos dados, foram utilizados quatro instrumentos de coleta de dados. $\mathrm{O}$ primeiro refere-se a um questionário para a caracterização dos sujeitos - dados sociodemográficos, o segundo refere-se à identificação do clima organizacional, o terceiro referese à identificação da cultura organizacional por fim a identificação da prevalência do estresse recente e atual. 
- Questionário sociodemográfico - Trata-se de um questionário elaborado pelas pesquisadoras para registrar os dados sociodemográficos, e assim caracterizar a população em estudo. É formado por questões que contemplam as seguintes variáveis: Sexo; Data de nascimento; Escolaridade; Situação conjugal; Profissão; Cargo que exerce no local de trabalho; Tempo de serviço; Número de vínculos empregatícios; Turno de trabalho; Plantões extras; Carga horária de trabalho semanal.

- Identificação do Clima Organizacional - A Escala de Clima Organizacional (ECO) é utilizada para identificar a estrutura empírica do construto em várias empresas, através dos cinco fatores. Este instrumento foi validado em 2004 na língua portuguesa (MARTINS, et. al., 2004). A Escala ECO é composta por 63 itens, divididos em 5 fatores, são eles: (MARTINS, et. al., 2004). Fator 1, "Apoio da chefia e da organização”, contém 21 itens que abordam a exigência de comportamentos de suporte afetivo, estrutural e operacional da chefia e da organização para com os empregados no desempenho diário de suas atividades no trabalho. Fator 2, "Recompensa", contém 13 itens abordando conteúdos relativos as formas de recompensa usadas pela empresa para premiar a qualidade, produtividade, o esforço e o desempenho do trabalhador. Fator 3 "Conforto físico", contém 13 itens relacionados com o ambiente físico, a segurança e o conforto proporcionados pela empresa aos funcionários. Fator 4 "Controle/Pressão", contém 9 itens relacionados com o controle e a pressão exercidos pela empresa e pelos supervisores sobre o comportamento e o desempenho dos funcionários. Fator 5 "Coesão entre colegas", contém por 7 itens relacionados com o trabalho em equipe e com o vínculo entre os colegas de trabalho. A escalas de 5 pontos, variando de "discordo totalmente" (1) a "concordo totalmente" (5). Os resultados devem ser verificados por fator, assim, haverá um resultado (ou média fatorial) para cada um dos fatores, ou seja, o diagnóstico do clima organizacional será feito baseando-se em cinco aspectos (os fatores da ECO). Para interpretá-los, foi considerada a média de 
cada fator, quanto maior for o valor de cada média fatorial mensurada mais esse fator estará presente na organização, dessa forma influenciando para um clima organizacional melhor ou pior (MARTINS, et. al., 2004).

Tabela 1 - Fatores, objetivos e questões da escala de clima organizacional ECO, Ribeirão Preto, SP, 2018.

\begin{tabular}{c|l|c}
\hline Fatores: & \multicolumn{1}{|c|}{ Objetivo: } & Questões: \\
\hline $\begin{array}{c}\text { F1 - Apoio da chefia e da } \\
\text { organização }\end{array}$ & $\begin{array}{l}\text { Abordam a exigência de comportamentos de suporte } \\
\text { afetivo, estrutural e operacional da chefia e da } \\
\text { organização para com os empregados no desempenho } \\
\text { diário de suas atividades no trabalho. }\end{array}$ & 21 \\
\hline F2 - Recompensa & $\begin{array}{l}\text { Abordam conteúdos relativos às formas de } \\
\text { recompensa usadas pela empresa para premiar a } \\
\text { qualidade, produtividade, o esforço e o desempenho } \\
\text { do trabalhador. }\end{array}$ & 13 \\
\hline F3 - Conforto físico & $\begin{array}{l}\text { Relacionados com o ambiente físico, a segurança e o } \\
\text { conforto proporcionados pela empresa aos } \\
\text { funcionários. }\end{array}$ & 13 \\
\hline F4 - Controle/Pressão & $\begin{array}{l}\text { Relacionados com o controle e a pressão exercidos } \\
\text { pela empresa e pelos supervisores sobre o } \\
\text { comportamento o desempenho dos funcionários }\end{array}$ & 9 \\
\hline F5 - Coesão entre colegas & $\begin{array}{l}\text { Relacionados com o trabalho em equipe e com o } \\
\text { vínculo entre os colegas de trabalho. }\end{array}$ & 7 \\
\hline Fon
\end{tabular}

Fonte: Autor, 2018

- Identificação da Cultura Organizacional - O Instrumento Brasileiro para Avaliação da Cultura Organizacional (IBACO) é voltado para a análise e compreensão da intricada e complexa rede de fenômenos relacionais e estruturais responsáveis pelo adequado funcionamento das organizações. Este instrumento foi validado em 2002 na língua portuguesa (FERREIRA, et. al., 2002). O instrumento IBACO é composto de 94 itens distribuídos em quatro dimensões correspondentes a valores, e outras três associadas a práticas organizacionais (FERREIRA, et. al., 2002). Dimensões sobre Valores: O Fator 1, "Profissionalismo cooperativo", contém 23 itens (1 - 23) associa-se à valorização dos empregados que executam suas tarefas com eficácia e competência, demonstrando espírito de colaboração, habilidade, dedicação, profissionalismo e capacidade de iniciativa, contribuição, desse 
modo, para o alcance das metas comuns da organização. O Fator 2, "Rigidez na estrutura hierárquica de poder", contém 13 itens (24 -36), os itens referenciam os valores presentes em organizações definidas por um sistema de autoridade centralizado e autoritário que dificulta o crescimento profissional e o reconhecimento do elemento humano. O Fator 3, "Profissionalismo competitivo e individualista", contém 8 itens (37 - 44), os itens denotam a valorização prioritária da competência, do desempenho e eficácia individual na execução de tarefas para a obtenção dos objetivos desejados, ainda que isso implique a necessidade de "passar por cima" dos colegas que almejam objetivos semelhantes. O Fator 4, "Satisfação e bemestar dos empregados", contém 11 itens (45 - 55), apresentam valores característicos de empresas que investem no bem-estar, satisfação e motivação dos empregados, procurando, assim, humanizar o local de trabalho e torna-lo agradável e prazeroso. Dimensões sobre Práticas Organizacionais: O Fator 1, "Práticas de integração externa", composto por 17 itens (56 - 72) voltados para o planejamento estratégico, tomada de decisões e atendimento ao cliente externo, com foco, portanto, nos escalões superiores da organização. O Fator 2, "Práticas de recompensa e treinamento", contém 14 itens (73 - 86) relacionados as práticas vinculadas aos clientes internos e aos sistemas de recompensas e treinamento adotados pela empresa. O Fator 3, "Práticas de relacionamento interpessoal" composto por 8 itens $(87$ - 94) voltado a práticas orientada para a promoção das relações interpessoais e satisfação dos empregados. A escalas de formato Likert de 5 pontos, variando de "não se aplica de modo nenhum à minha empresa" (1) a "aplica-se totalmente à minha empresa" (5), para interpretálos, deve ser feito o cálculo da soma dos pontos atribuídos por itens de cada fator e dividir pelo número de itens que compões cada fatos, dessa forma será obtido a média de cada fator. Para interpretação dos resultados considerou-se que os escores em todos os fatores podem variar de 1 a 5 , sendo que, quanto maior o resultado, maior o grau em que o valor ou prática 
organizacional mensurada pelo fator está presente na organização avaliada

(FERREIRA, et. al., 2002; FERREIRA, et. al., 2008).

Tabela 2 - Fatores, objetivos e questões da escala de clima organizacional ECO, Ribeirão Preto, SP, 2018.

\begin{tabular}{|c|c|c|c|}
\hline & Fatores: & Objetivo: & Questões: \\
\hline \multirow{4}{*}{$\begin{array}{c}\text { Dimensões sobre } \\
\text { Valores }\end{array}$} & $\begin{array}{c}1 \text { - Profissionalismo } \\
\text { cooperativo }\end{array}$ & $\begin{array}{l}\text { Associa-se à valorização dos empregados } \\
\text { que executam suas tarefas com eficácia e } \\
\text { competência, demonstrando espírito de } \\
\text { colaboração, habilidade, dedicação, } \\
\text { profissionalismo e capacidade de iniciativa, } \\
\text { contribuição, desse modo, para o alcance } \\
\text { das metas comuns da organização. }\end{array}$ & 23 \\
\hline & $\begin{array}{l}2 \text { - Rigidez na } \\
\text { estrutura hierárquica } \\
\text { de poder }\end{array}$ & $\begin{array}{l}\text { Os itens referenciam os valores presentes } \\
\text { em organizações definidas por um sistema } \\
\text { de autoridade centralizado e autoritário que } \\
\text { dificulta o crescimento profissional e o } \\
\text { reconhecimento do elemento humano. }\end{array}$ & 13 \\
\hline & $\begin{array}{l}3 \text { - Profissionalismo } \\
\text { competitivo e } \\
\text { individualista }\end{array}$ & $\begin{array}{l}\text { Os itens denotam a valorização prioritária } \\
\text { da competência, do desempenho e eficácia } \\
\text { individual na execução de tarefas para a } \\
\text { obtenção dos objetivos desejados, ainda } \\
\text { que isso implique a necessidade de "passar } \\
\text { por cima" dos colegas que almejam } \\
\text { objetivos semelhantes. }\end{array}$ & 8 \\
\hline & $\begin{array}{l}4 \text { - Satisfação e bem- } \\
\text { estar dos empregados }\end{array}$ & $\begin{array}{l}\text { Apresentam valores característicos de } \\
\text { empresas que investem no bem-estar, } \\
\text { satisfação e motivação dos empregados, } \\
\text { procurando, assim, humanizar o local de } \\
\text { trabalho e torna-lo agradável e prazeroso. }\end{array}$ & 11 \\
\hline \multirow{3}{*}{$\begin{array}{l}\text { Dimensões sobre } \\
\text { Práticas } \\
\text { Organizacionais }\end{array}$} & $\begin{array}{c}1 \text { - Práticas de } \\
\text { integração externa }\end{array}$ & $\begin{array}{l}\text { Voltados para o planejamento estratégico, } \\
\text { tomada de decisões e atendimento ao } \\
\text { cliente externo, com foco, portanto, nos } \\
\text { escalões superiores da organização. }\end{array}$ & 17 \\
\hline & $\begin{array}{l}2 \text { - Práticas de } \\
\text { recompensa e } \\
\text { treinamento }\end{array}$ & $\begin{array}{l}\text { Relacionados as práticas vinculadas aos } \\
\text { clientes internos e aos sistemas de } \\
\text { recompensas e treinamento adotados pela } \\
\text { empresa. }\end{array}$ & 14 \\
\hline & $\begin{array}{l}3 \text { - Práticas de } \\
\text { relacionamento } \\
\text { interpessoal }\end{array}$ & $\begin{array}{l}\text { Voltado a práticas orientadas para a } \\
\text { promoção das relações interpessoais } \mathrm{e} \\
\text { satisfação dos empregados. }\end{array}$ & 8 \\
\hline
\end{tabular}

Fonte: Autor, 2018 
- Instrumento para avaliar a Prevalência do estresse atual (Inventário de Sintomas de Stress para adultos (ISSL) - Esse inventário toma por base os princípios da teoria de Selye, destina-se ao uso de jovens e adultos e visa identificar a sintomatologia que o indivíduo apresenta (se somático ou psicológico), avaliando se ele possui sintomas de estresse, o tipo de sintoma predominante e a fase do estresse em que se encontra, em momentos distintos: últimas 24 horas (F1-12; P-3), último semana (F-10; P-5), últimos mês (F-12; P11). O ISSL é composto de três partes e se referem respectivamente às quatro fases do stress: alerta (fase 1): se 7 ou mais sintomas (itens), apontados nas últimas 24 horas; resistência e quase-exaustão (fase 2): se 4 ou mais sintomas (itens), apontados na última semana; exaustão (fase 3): se 9 sintomas (itens), apontados no último mês (LIPP, et. al., 1994). Foi elaborado por Lipp, validado na língua portuguesa por Lipp e Guevara (1994) e padronizado por Lipp (2000). A presença de estresse pode ser constatada se qualquer dos escores brutos atingir os limites determinados (maior que 6 na últimas 24 horas, maior que 3 na última semana, maior que 8 no último mês). (LIPP, et. al.,1994; LIPP, 2000)

\subsection{Procedimentos da coleta de dados}

A coleta ocorreu de novembro de 2017 a março de 2018. Antes da abordagem do participante foi solicitada autorização para o profissional responsável de cada setor.

Foram fornecidos, a cada participante, esclarecimentos quanto a natureza da pesquisa, objetivos, procedimentos, garantias éticas e solicitada a sua colaboração voluntária. O tempo total necessário à participação foi de 40 minutos aproximadamente. A coleta de dados foi efetuada pela equipe de pesquisa e ocorreu da seguinte forma:

a) $\mathrm{O}$ primeiro encontro era de 10 minutos, aproximadamente. $\mathrm{O}$ participante assinava o termo de consentimento, após respondia ao questionário sociodemográfico, sendo o preenchimento deste realizado pela pesquisadora. Após as orientações quanto ao procedimento dos demais instrumentos, um envelope era entregue ao participante e acordado uma data e horário para devolução.

b) A previsão de tempo para o preenchimento desses instrumentos era de 40 minutos. 


\subsection{Análise estatística}

Foi realizada estatística descritiva das características da população e das variáveis estudadas por meio de: distribuição de frequências, números absolutos e percentuais, mínimo e máximo, incluindo a medida de tendência central (média e mediana) e de dispersão (desvio padrão), para as variáveis quantitativas e análise univariada (tabelas de frequência) e bivariada (tabelas de contingência), para variáveis qualitativas. Para a análise dos resultados, serão utilizados testes paramétricos e não paramétricos, levando-se em consideração a natureza das distribuições dos valores, ou a variabilidade das medidas efetuadas, uma vez que os valores individuais são originários de pontos de uma mesma escala (POLIT, et. al., 2004). Será utilizando o teste de associação qui-quadrado $\left(\chi^{2}\right)$.

\subsection{Riscos e benefícios do estudo}

Os riscos que o estudo puderam acarretar ao profissional estariam relacionados às questões presentes nos instrumentos. Caso o participante se sentisse constrangido (a), triste ou sensível por causa das perguntas, o pesquisador esteve disponível por contato telefônico e pessoalmente para acolher a demanda (avaliando e auxiliando o participante a buscar a melhor solução possível, inclusive a buscar suporte profissional se necessário). Os benefícios do estudo são indiretos e relacionados aos possíveis avanços gerados pelos resultados do estudo para intervenções no cuidado à saúde do profissional.

\subsection{Aspectos éticos}

Este estudo possui aprovação do Comitê de Ética e Pesquisa da Escola de Enfermagem de Ribeirão Preto - Universidade de São Paulo (Protocolo CAAE: 65948417.1.0000.5393) e autorização do serviço. Foi assegurado aos participantes: a voluntariedade para participar do estudo; recusa da participação sem prejuízo algum; liberdade de retirar seu consentimento a qualquer momento da pesquisa; informações sobre a justificativa, objetivos, procedimentos, riscos e benefícios do estudo; ausência de remuneração e gastos; segurança de não serem 
identificados; uma via do Termo de Consentimento Livre e Esclarecido (TCLE) devidamente assinado. Respeitando os parâmetros éticos para investigações envolvendo seres humanos, especialmente a Resolução n 466/12 (BRASIL, 2012). 
6. RESULTADOS 


\section{RESULTADOS}

\subsection{Caracterização dos Participantes}

Entre os profissionais elegíveis para o estudo, foram convidados 212 e destes 155 compuseram a amostra final. Esta amostra foi composta principalmente por técnicos de enfermagem $(44,5 \%)$, seguidos por enfermeiros $(29,7 \%)$, auxiliares de enfermagem $(17,4 \%)$ e médicos $(8,4 \%)$.

A idade média dos profissionais foi de 42,6 anos ( \pm dp 11,27), variando entre 22 a 84 anos. Observou-se que 43,23\% dos participantes possuíam ensino médio completo e 32,90\% superior completo, $63 \%$ eram casados ou com um companheiro fixo conforme detalhado na tabela 3 a seguir.

Tabela 3: Caracterização dos profissionais da saúde participantes do estudo, segundo as variáveis sexo, idade, escolaridade, estado civil, Ribeirão Preto, SP, 2018.

\begin{tabular}{c|l|l|l}
\hline VARIÁ VEIS & \multicolumn{1}{|c|}{ CATEGORIAS } & \multicolumn{1}{c|}{$\mathbf{n}(\%)$} & MÉDIA $\pm \mathbf{d p}$ \\
\hline \multirow{2}{*}{ Gênero } & Feminino & $114(73,5)$ & \\
& Masculino & $41(26,5)$ & \\
\hline Idade & 22 a 84 anos & $155(100)$ & $42,65 \pm 11,27$ \\
\hline \multirow{5}{*}{ Escolaridade } & Fundamental completo & $2(1,3)$ & \\
& Médio incompleto & $3(1,9)$ & \\
& Médio completo & $67(43,2)$ & \\
& Superior incompleto & $23(14,8)$ & \\
& Superior completo & $51(32,9)$ & \\
& Pós Graduação & $9(5,8)$ & \\
\hline \multirow{3}{*}{ Estado civil } & Solteiro & $32(20,6)$ & \\
& Casado/com companheiro fixo & $98(63,2)$ & \\
& Separado/divorciado & $24(15,5)$ & \\
& Viúvo & $1(6)$ & \\
\hline
\end{tabular}

O tempo de serviço dos profissionais participantes variou entre 1 à 46 anos (média 12,21 \pm dp 10,42), sendo que $42,6 \%$ dos profissionais trabalhavam no turno noturno, $33,5 \%$ no diurno. Além disso, 61,3\% dos profissionais possuíam apenas um vínculo empregatício e 38,7\% possuíam dois ou mais vínculos (tabela 4 a seguir). 
Tabela 4: Caracterização dos profissionais da saúde participantes do estudo, segundo as variáveis relacionadas à profissão, Ribeirão Preto, SP, 2018.

\begin{tabular}{|c|c|c|c|}
\hline VARIÁVEIS & CATEGORIAS & $\mathbf{n}(\%)$ & MÉDIA \pm dp \\
\hline \multirow{4}{*}{ Profissão } & Enfermeiro & $46(29,7)$ & \\
\hline & Técnico de enfermagem & $69(44,5)$ & \\
\hline & Auxiliar de enfermagem & $27(17,4)$ & \\
\hline & Médico & $13(8,4)$ & \\
\hline \multirow{4}{*}{ Cargo que exerce no local de trabalho } & Enfermeiro & $42(27,1)$ & \\
\hline & Técnico de enfermagem & $67(43,2)$ & \\
\hline & Auxiliar de enfermagem & $33(21,3)$ & \\
\hline & Médico & $13(8,4)$ & \\
\hline Tempo de serviço & 1 à 46 anos & & $12,21 \pm 10,423$ \\
\hline \multirow{2}{*}{ Número de vínculos empregatícios } & Um vínculo & $95(61,3)$ & \\
\hline & Dois ou mais vínculos & $60(38,7)$ & \\
\hline \multirow{3}{*}{ Turno de trabalho } & Diurno & $52(33,5)$ & \\
\hline & Noturno & $66(42,6)$ & \\
\hline & Ambos & $37(23,9)$ & \\
\hline $\begin{array}{l}\text { Plantões extras } \\
\end{array}$ & 0 à 30 horas & & $6,34 \pm 7,20$ \\
\hline Carga horária de trabalho semanal & 20 à 60 horas & & $33,61 \pm 7,047$ \\
\hline
\end{tabular}

Com relação aos setores de trabalho entre os profissionais participantes, foi realizado um agrupamento de setor conforme a complexidade do cuidado observado na tabela 5, destacando-se $55 \%$ dos profissionais trabalhado em "Unidade de Tratamento intensivo" incluindo os setores da Unidade de Emergência de maior complexidade (CTI Adulto, CTI Pediátrico, UCO, Sala de Urgência, Queimados, Bloco Cirúrgico e Centro Cirúrgico); seguido por 37\% dos profissionais trabalhado nas "Enfermarias" (Clínica médica, Hemodiálise, Psiquiatria, Clínica cirúrgica, Neurologia, Enfermaria pediátrica e MI Pediátrica) e por fim $8 \%$ destes trabalhando em "Unidade de Controle de materiais, exames e administrativo" (Imagens - TMO, Central de material, Descontaminação, Banco de sangue, CCIH, Unidade respiratória). 
Tabela 5: Setores de trabalho em agrupamento por complexidade dos profissionais da saúde participantes do estudo, Ribeirão Preto, SP, 2018.

\begin{tabular}{|c|c|c|}
\hline AGRUPAMENTO & LOCAL & $\mathbf{n}(\%)$ \\
\hline Unidade de tratamento intensivo & $\begin{array}{l}\text { CTI Adulto; } \\
\text { CTI Pediátrico; } \\
\text { UCO; } \\
\text { Sala de Urgência; } \\
\text { Queimados; } \\
\text { Bloco cirúrgico; } \\
\text { Centro Cirúrgico. }\end{array}$ & 55,0 \\
\hline Unidade de controle de materiais, exames e administrativo & $\begin{array}{l}\text { Imagens - TMO; } \\
\text { Central de material; } \\
\text { Descontaminação; } \\
\text { Banco de sangue; } \\
\text { CCIH; } \\
\text { Unidade respiratória. }\end{array}$ & 8,0 \\
\hline Enfermarias & $\begin{array}{l}\text { Clínica médica; } \\
\text { Hemodiálise; } \\
\text { Psiquiatria; } \\
\text { Clínica cirúrgica; } \\
\text { Neurologia; } \\
\text { Enfermaria pediátrica; } \\
\text { Moléstia infecciosa pediátrica. }\end{array}$ & 37,0 \\
\hline
\end{tabular}

$\mathbf{N}=155$

\subsection{Estresse atual entre os profissionais do serviço de emergência}

$\mathrm{Na}$ amostra estudada observou-se $47,1 \%$ de profissionais com estresse atual, sendo que entre estes profissionais que tinham estresse: $82,2 \%$ eram mulheres, $57,5 \%$ com escolaridade de nível superior incompleto ou completo, 56,2\% com companheiro fixo. Com relação a características do trabalho dos profissionais com estresse 43,8\% eram técnicos de enfermagem, $34,2 \%$ eram enfermeiros, $15,1 \%$ eram auxiliares de enfermagem e 6,8\% eram médicos, e $37 \%$ trabalhavam no turno noturno.

Além disso, os resultados evidenciaram que os profissionais com estresse estavam em sua maioria na fase de resistência $(76,7 \%), 17,8 \%$ na fase de quase-exaustão, $4,1 \%$ na fase de exaustão e 1,4\% na fase de alerta. Com relação à predominância dos sintomas do estresse 57,5\% tinham sintomas psicológicos, 34,3\% apresentaram sintomas físicos e 8,2\% ambos os sintomas (gráfico 1). 


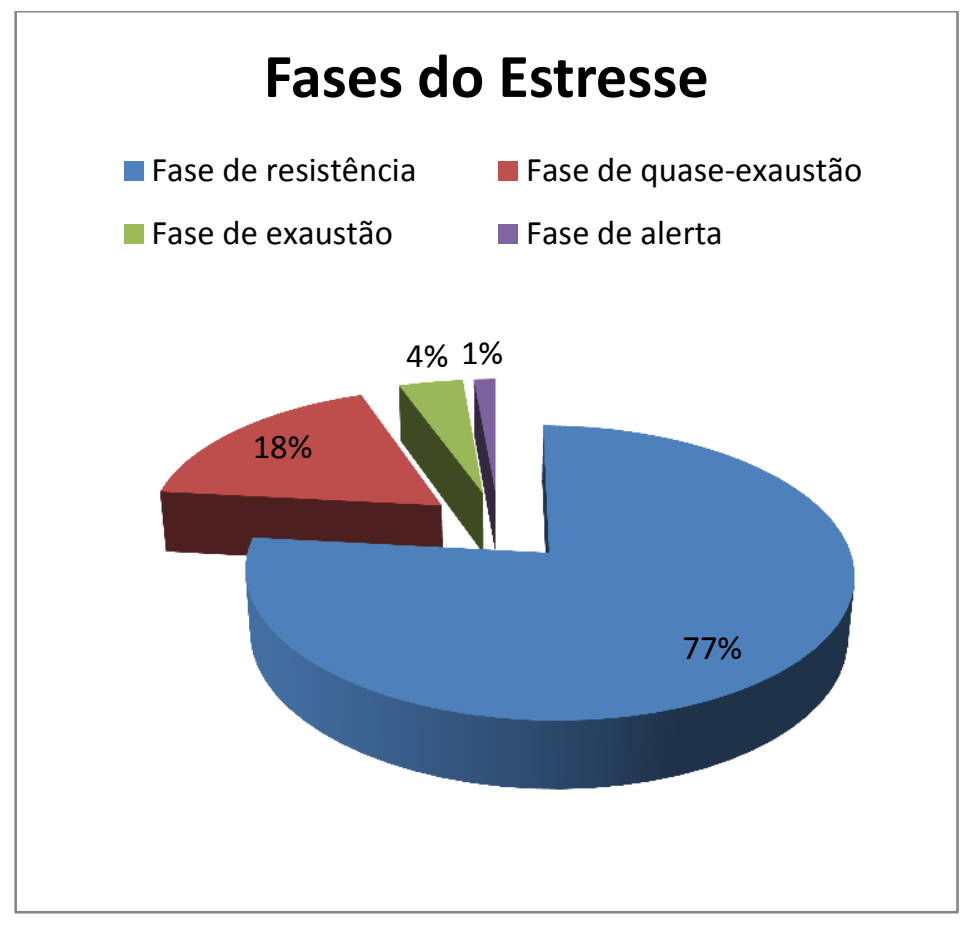

\section{Sintomas do Estresse}

- Sintomas psicológicos $\square$ Sintomas físicos

Ambos os sintomas

Gráfico 1: Comparativo entre as fases e os sintomas do estresse dos profissionais da saúde participantes do estudo, Ribeirão Preto, SP, 2018.

\subsection{Cultura organizacional e a relação com o estresse atual nos profissionais do serviço de emergência}

Para análise da cultura organizacional foram consideradas as sete dimensões avaliadas pelo IBACO representadas através dos quatro valores correspondentes aos fatores 1, 2, 3 e 4 e também através das três práticas correspondentes aos fatores 5, 6 e 7. Conforme detalhado no gráfico 2 que segue.

Com relação aos valores da cultura organizacional observou-se que o Profissionalismo cooperativo (F1) teve uma média de 2,55, o valor relacionado a Rigidez na estrutura hierárquica de poder (F2) teve uma média de 2,89, o valor relacionado ao Profissionalismo competitivo e individualista (F3) teve uma média de 2,23, o valor relacionado a Satisfação e bem-estar dos empregados (F4) teve uma média 2,13.

Com relação as práticas organizacionais que constituem a cultura organizacional do serviço, observou-se que as Práticas de integração externa (F5) tiveram uma média de 2,85; as 
Práticas de recompensa e treinamento (F6) tiveram uma média de 1,96; e por fim as Práticas de relacionamento interpessoal (F7) tiveram uma média de 2,2.

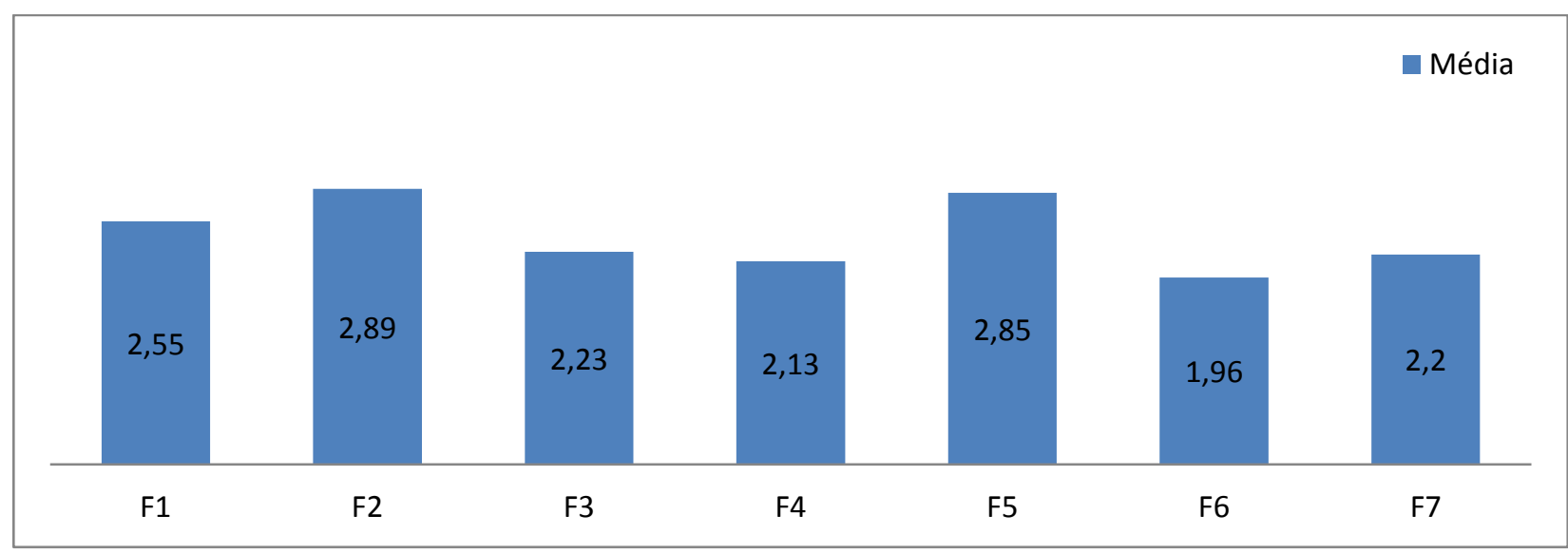

Gráfico 2: Média por fatores da cultura organizacional dos profissionais do serviço de emergência, Ribeirão Preto, SP, 2018.

$\mathrm{N}=155$ profissionais. Fatores da escala de cultura organizacional (IBACO): $\mathrm{F} 1=$ Profissionalismo cooperativo; F2 = Rigidez na estrutura hierárquica de poder; F3= Profissionalismo competitivo e individualista; F4 = Satisfação e bem-estar dos empregados; F5 = Práticas de integração externa; F6 = Práticas de recompensa e treinamento; F7 = Práticas de relacionamento interpessoal.

Considerando-se a análise da cultura organizacional nos fatores F1, F4, F5, F6 e F7 é possível inferir que na opinião dos profissionais investigados a cultura organizacional no serviço não é muito boa. Uma vez que estes fatores representam valores e práticas que favorecem uma melhor cultura organizacional. Os resultados evidenciaram que as médias observadas nestes fatores estavam entre dois e três aproximadamente, sendo que, médias mais próximas a cinco representariam uma melhor cultura organizacional.

Destacando-se ainda que o fatore 2 "Rigidez na estrutura hierárquica de poder" foi valor que mais esteve presente na cultura organizacional do serviço na opinião dos profissionais.

Na tabela 6 apresenta-se um comparativo do escore médio entre a cultura organizacional e profissionais com e sem estresse atual. Destaca-se maiores escores médios relacionados à cultura organizacional e o estresse atual, notadamente no fator 2 "Rigidez na estrutura hierárquica de poder" (média 3,02 \pm dp 0,77) e no fator 3 "Profissionalismo competitivo e individualista" $(2,28$ $\pm \mathrm{dp} 0,66)$. 
Tabela 6: Cultura organizacional e a relação com o estresse atual nos profissionais do serviço de emergência, Ribeirão Preto, SP, 2018.

\begin{tabular}{c|c|c|c|c}
\hline FATORES & \multicolumn{3}{|c}{ ESTRESSE } \\
\hline \multirow{2}{*}{ Profissionalismo cooperativo } & & Com estresse & Sem estresse & Total \\
\hline \multirow{2}{*}{ Rigidez na estrutura hierárquica de poder } & $\mathrm{n}(\%)$ & 73 & 82 & 155 \\
\cline { 2 - 5 } & $\mathrm{Media}(\mathrm{dp})$ & $2,389(0,733)$ & $2,691(0,668)$ & \\
\cline { 2 - 5 } & $\mathrm{Media}(\mathrm{dp})$ & $\mathbf{3 , 0 2 6}(\mathbf{0 , 7 7 2}) *$ & $2,839(0,730$ & \\
\hline \multirow{2}{*}{ Profissionalismo competitivo e individualista } & $\mathrm{n}(\%)$ & 73 & 81 & 154 \\
\cline { 2 - 5 } & $\mathrm{Media}(\mathrm{dp})$ & $\mathbf{2 , 2 8 6}(\mathbf{0 , 6 6 5}) *$ & $2,217(0,691$ & \\
\hline \multirow{2}{*}{ Satisfação e bem-estar dos empregados } & $\mathrm{n}(\%)$ & 73 & 80 & 153 \\
\cline { 2 - 5 } & $\mathrm{Media}(\mathrm{dp})$ & $2,053(0,774$ & $2,258(0,677$ & \\
\hline \multirow{2}{*}{ Práticas de integração externa } & $\mathrm{n}(\%)$ & 73 & 81 & 154 \\
\cline { 2 - 5 } & $\mathrm{Media}(\mathrm{dp})$ & $2,895(0,648$ & $2,899(0,685$ & \\
\hline \multirow{2}{*}{ Práticas de recompensa e treinamento } & $\mathrm{n}(\%)$ & 73 & 80 & 153 \\
\cline { 2 - 5 } & $\mathrm{Media}(\mathrm{dp})$ & $1,908(0,662$ & $2,053(0,641$ & \\
\hline \multirow{2}{*}{ Práticas de relacionamento interpessoal } & $\mathrm{n}(\%)$ & 73 & 80 & 153 \\
\cline { 2 - 5 } & $\mathrm{Media}(\mathrm{dp})$ & $2,159(0,778$ & $2,283(0,787$ & \\
\hline
\end{tabular}

*Destaque para maiores escores médios da cultura em profissionais com estresse.

Porém, as análises estatísticas realizadas evidenciaram que houve associação entre cultura organizacional (fatores 1 e 4) e estresse atual entre os profissionais da saúde de serviços de emergência, conforme detalhado na tabela 7 que segue. Houve, portanto, diferença estatisticamente significativa entre as medianas dos escores da cultura organizacional entre os profissionais com e sem estresse. 
Tabela 7: Teste de associação entre Cultura organizacional e o estresse atual nos profissionais do serviço de emergência, Ribeirão Preto, SP, 2018.

\begin{tabular}{|c|c|c|c|c|c|}
\hline FATOR & $\begin{array}{l}\text { ESTRESSE } \\
\text { ATUAL }\end{array}$ & $\mathbf{N}$ & $\begin{array}{l}\text { POSTO } \\
\text { MÉDIO }\end{array}$ & $\begin{array}{c}\text { SOMA DA } \\
\text { CLASSIFICAÇÕES }\end{array}$ & $\begin{array}{l}\text { NÍVEL DE } \\
\text { SIGNIFICÂNCIA }\end{array}$ \\
\hline \multirow{3}{*}{ Profissionalismo cooperativo } & Não & 82 & 86,72 & 7111,00 & \multirow{3}{*}{$0,010 *$} \\
\hline & Sim & 73 & 68,21 & 4979,00 & \\
\hline & Total & \multicolumn{3}{|r|}{155} & \\
\hline \multirow{3}{*}{$\begin{array}{c}\text { Rigidez na estrutura hierárquica } \\
\text { de poder }\end{array}$} & Não & 80 & 70,44 & 5635,00 & \multirow{3}{*}{0,055} \\
\hline & Sim & 73 & 84,19 & 6146,00 & \\
\hline & Total & \multicolumn{3}{|r|}{153} & \\
\hline \multirow{3}{*}{$\begin{array}{c}\text { Profissionalismo competitivo e } \\
\text { individualista }\end{array}$} & Não & 81 & 75,78 & 6138,50 & \multirow{3}{*}{0,614} \\
\hline & Sim & 73 & 79,40 & 5796,50 & \\
\hline & Total & \multicolumn{3}{|r|}{154} & \\
\hline \multirow{3}{*}{$\begin{array}{l}\text { Satisfação e bem-estar dos } \\
\text { empregados }\end{array}$} & Não & 80 & 83,76 & 6700,50 & \multirow{3}{*}{$0,048^{*}$} \\
\hline & Sim & 73 & 69,60 & 5080,50 & \\
\hline & Total & 153 & & & \\
\hline \multirow{3}{*}{ Práticas de integração externa } & Não & 81 & 77,78 & 6300,50 & \multirow{3}{*}{0,934} \\
\hline & Sim & 73 & 77,18 & 5634,50 & \\
\hline & Total & & & 154 & \\
\hline \multirow{3}{*}{$\begin{array}{c}\text { Práticas de recompensa e } \\
\text { treinamento }\end{array}$} & Não & 80 & 82,28 & 6582,00 & \multirow{3}{*}{0,123} \\
\hline & Sim & 73 & 71,22 & 5199,00 & \\
\hline & Total & 153 & & & \\
\hline \multirow{3}{*}{$\begin{array}{c}\text { Práticas de relacionamento } \\
\text { interpessoal }\end{array}$} & Não & 80 & 80,21 & 6417,00 & \multirow{3}{*}{0,347} \\
\hline & Sim & 73 & 73,48 & 5364,00 & \\
\hline & Total & \multicolumn{3}{|r|}{153} & \\
\hline
\end{tabular}

Teste Mann-Whitney,

* nível de significância $\mathrm{p} \leq 0,05$

Destaca-se assim, que a cultura organizacional relacionada ao "profissionalismo cooperativo" ( $p=0,010)$ e à "satisfação e bem-estar dos empregados" ( $p=0,048)$ estava associada ao estresse atual nestes profissionais.

\subsection{Clima organizacional e a relação com o estresse atual nos profissionais do serviço de emergência}

No gráfico 3 que segue, detalha-se as médias para os fatores que representam o clima organizacional entre os profissionais do serviço de emergência investigados. Os resultados permitem destacar os fatores 3, 4 e 5 com maiores médias. Assim, "Conforto físico" $(3,13)$, 
Controle/pressão teve média de 3,05, e o fator relacionado a Coesão entre colegas teve média de 3,1. Pode-se destacar também que o fator 2 "Recompensa" foi o que apresentou menor média.

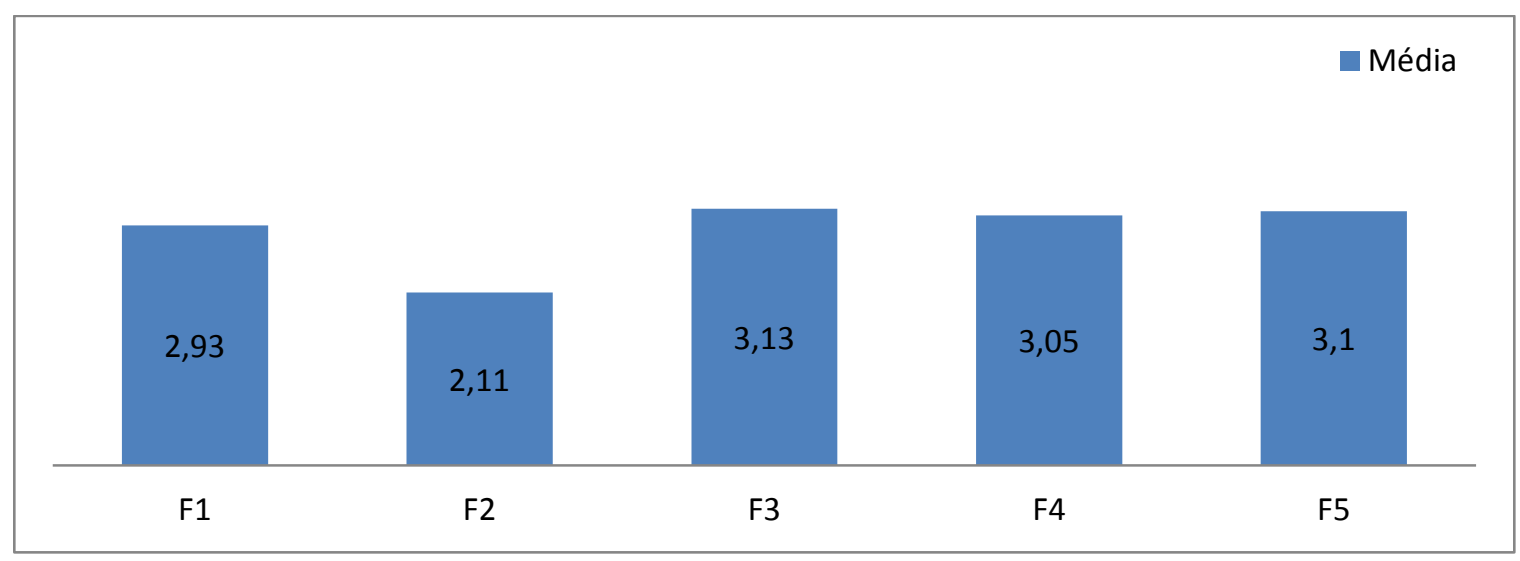

Gráfico 3: Média por fatores do clima organizacional dos profissionais do serviço de emergência, Ribeirão Preto, SP, 2018.

$\mathrm{N}=155$ profissionais. Fatores da escala clima organizacional (ECO): F1 = Apoio da chefia e da organização; F2 = Recompensa; F3 = Conforto físico; F4 = Controle/pressão; F5 = Coesão entre colegas

Na tabela 8 apresenta-se um comparativo do escore médio entre o clima organizacional e profissionais com ou sem estresse atual. Destaca-se maiores escores médios do clima organizacional e o estresse atual no fator 1 "Apoio da chefia e da organização" (média 2,69 \pm dp 0,71), fator 2 "Recompensa" (1,91 $\pm \mathrm{dp} 0,63)$, fator 3 “Conforto físico" $(2,97 \pm \mathrm{dp} 0,84)$ e fator 5 “Coesão entre colegas” $(2,95 \pm$ dp 0,72$)$.

Tabela 8: Clima organizacional e a relação com o estresse atual nos profissionais do serviço de emergência, Ribeirão Preto, SP, 2018.

\begin{tabular}{|cccccccc}
\hline FATORES & ESTRESSE & N & MÉDIA & DP & MINIMO & MAXIMO \\
\hline \multirow{2}{*}{ Apoio da chefia e da organização } & Com estresse & 73 & $\mathbf{2 , 6 9 4}$ & 0,711 & 1,100 & 4,450 \\
& Sem estresse & 82 & 3,103 & 0,675 & 1,250 & 5,000 \\
\multirow{2}{*}{ Recompensa } & Com estresse & 73 & $\mathbf{1 , 9 1 4}$ & 0,635 & 1,000 & 3,769 \\
& Sem estresse & 82 & 2,301 & 0,633 & 1,000 & 4,154 \\
\multirow{2}{*}{ Conforto físico } & Com estresse & 73 & $\mathbf{2 , 9 7 4}$ & 0,842 & 1,000 & 4,769 \\
& Sem estresse & 82 & 3,280 & 0,566 & 1,308 & 5,000 \\
Controle/pressão & Com estresse & 73 & 3,090 & 0,608 & 1,444 & 4,556 \\
& Sem estresse & $81^{*}$ & 3,061 & 0,615 & 1,444 & 4,667 \\
\multirow{2}{*}{ Coesão entre colegas } & Com estresse & 73 & $\mathbf{2 , 9 5 9}$ & 0,723 & 1,000 & 4,429 \\
& Sem estresse & $81^{*}$ & 3,270 & 0,701 & 1,857 & 5,000 \\
\hline
\end{tabular}


Nos fatores do clima organizacional investigados é possível observar menores médias entre os profissionais com estresse, exceto no fator "Controle/pressão". Destacando-se que "Apoio da chefia e da organização" (média 2,694), "Recompensa" (1,914), "Conforto físico" (média 2,974) e "Coesão entre colegas" $(2,959)$ foram fatores com médias mais distantes de cinco, o que indica um clima organizacional ruim.

As análises estatísticas realizadas evidenciaram que houve associação entre o clima organizacional (fatores 1, 2, 3 e 5) e estresse atual entre os profissionais da saúde de serviços de emergência, conforme detalhado na tabela 9 que segue. Houve, portanto, diferença estatisticamente significativa entre as médias dos escores do clima organizacional entre os profissionais com e sem estresse.

Tabela 9: Teste de associação entre Clima organizacional e o estresse atual nos profissionais do serviço de emergência, Ribeirão Preto, SP, 2018.

\begin{tabular}{|c|c|c|c|c|c|}
\hline FATOR & $\begin{array}{c}\text { ESTRESSE } \\
\text { ATUAL }\end{array}$ & $\mathbf{N}$ & $\begin{array}{l}\text { POSTO } \\
\text { MÉDIO }\end{array}$ & $\begin{array}{c}\text { SOMA DA } \\
\text { CLASSIFICAÇÕES }\end{array}$ & \\
\hline \multirow{3}{*}{$\begin{array}{l}\text { Apoio da chefia e da } \\
\text { organização }\end{array}$} & Não & 82 & 89,81 & 7364,50 & \multirow{3}{*}{$0,001^{*}$} \\
\hline & Sim & 73 & 64,73 & 4725,50 & \\
\hline & Total & \multicolumn{3}{|r|}{155} & \\
\hline \multirow{3}{*}{ Recompensa } & Não & 82 & 90,22 & 7398,00 & \multirow{3}{*}{$0,000^{*}$} \\
\hline & Sim & 73 & 64,27 & 4692,00 & \\
\hline & Total & \multicolumn{3}{|r|}{155} & \\
\hline \multirow{3}{*}{ Conforto físico } & Não & 82 & 85,73 & 7029,50 & \multirow{3}{*}{$0,023^{*}$} \\
\hline & Sim & 73 & 69,32 & 5060,50 & \\
\hline & Total & \multicolumn{3}{|r|}{155} & \\
\hline \multirow{3}{*}{ Controle/pressão } & Não & 81 & 76,26 & 6177,00 & \multirow{3}{*}{0,716} \\
\hline & Sim & 73 & 78,88 & 5758,00 & \\
\hline & Total & \multicolumn{3}{|r|}{154} & \\
\hline \multirow{3}{*}{ Coesão entre colegas } & Não & 81 & 86,16 & 6979,00 & \multirow{3}{*}{$0,011^{*}$} \\
\hline & Sim & 73 & 67,89 & 4956,00 & \\
\hline & Total & \multicolumn{3}{|r|}{154} & \\
\hline
\end{tabular}

Teste Mann-Whitney, * nível de significância $\mathrm{p} \leq 0,05$

Destaca-se assim, que o clima organizacional relacionado ao "apoio da chefia e da organização" ( $p=0,001)$, "recompensa" ( $p=0,000)$, “conforto físico" ( $p=0,023)$ e à "coesão entre colegas" $(p=0,011)$ estava associado ao estresse atual nestes profissionais. 


\subsection{Associação do estresse com variáveis sócio-demográficas e de trabalho, nos profissionais} do serviço de emergência

Os resultados evidenciaram que nas análises entre o estresse com as variáveis sóciodemográficas e de trabalho, apenas a variável sexo esteve associada com o estresse. Observou-se que entre os profissionais que tinham estresse 52,6\% eram do sexo feminino e entre os profissionais sem estresse 68,3\% eram do sexo masculino. Alem disso, dos 52,6\% dos profissionais com estresse 56,1\% eram casados ou com companheiro fixo, 57,5\% com superior incompleto ou superior completo, 43,8\% eram técnicos de enfermagem, 34,2\% eram enfermeiros, $15,0 \%$ eram auxiliares de enfermagem e 6,8\% eram médicos. O turno noturno foi o que mais prevaleceu entre os profissionais com estresse com 36,9\% desta população. Conforme detalhado na tabela 10 .

Tabela 10: Associação do estresse entre variáveis sócio-demográficas e de trabalho, cultura e clima organizacional nos profissionais do serviço de emergência, Ribeirão Preto, SP, 2018

\begin{tabular}{|c|c|c|c|c|}
\hline VARIÁVEL & CARACTERÍSTICAS & $\begin{array}{c}\text { SEM } \\
\text { ESTRESSE } \\
\text { n(\%) }\end{array}$ & $\begin{array}{c}\text { COM ESTRESSE } \\
\text { n(\%) }\end{array}$ & $\begin{array}{c}\text { NÍVEL DE } \\
\text { SIGNIFICANCIA (P) }\end{array}$ \\
\hline \multirow{2}{*}{ Sexo } & Masculino & $28(68,3)$ & $13(31,7)$ & \multirow{2}{*}{$0,021 *$} \\
\hline & Feminino & $54(47,4)$ & $60(52,6)$ & \\
\hline \multirow{4}{*}{$\begin{array}{l}\text { Situação } \\
\text { conjugal }\end{array}$} & $\begin{array}{l}\text { Solteiro } \\
\end{array}$ & $12(14,6)$ & $20(27,3)$ & \multirow{4}{*}{0,085} \\
\hline & $\begin{array}{l}\text { Casado/Com Companheiro } \\
\text { Fixo }\end{array}$ & $57(69,5)$ & $41(56,1)$ & \\
\hline & Separado/Divorciado & $13(15,8)$ & $11(15,0)$ & \\
\hline & Viúvo & $0(0,0)$ & $1(1,3)$ & \\
\hline \multirow{2}{*}{ Escolaridade } & Médio Completo ou menos & $41(50)$ & $31(42,4)$ & \multirow[t]{2}{*}{0,348} \\
\hline & Superior Incompleto ou mais & $41(50)$ & $42(57,5)$ & \\
\hline \multirow{4}{*}{ Profissão } & Enfermeiro & $21(25,6)$ & $25(34,2)$ & \multirow{4}{*}{0,612} \\
\hline & Técnico de Enfermagem & $37(45,1)$ & $32(43,8)$ & \\
\hline & Auxiliar de Enfermagem & $16(19,5)$ & $11(15,0)$ & \\
\hline & Médico & $8(9,7)$ & $5(6,8)$ & \\
\hline \multirow{4}{*}{$\begin{array}{l}\text { Cargo que } \\
\text { exerce }\end{array}$} & Enfermeiro & $19(23,1)$ & $23(31,5)$ & \multirow{4}{*}{0,668} \\
\hline & Técnico de Enfermagem & $37(45,1)$ & $30(41,0)$ & \\
\hline & Auxiliar de Enfermagem & $18(21,9)$ & $15(20,5)$ & \\
\hline & Médico & $8(9,7)$ & $5(6,8)$ & \\
\hline $\begin{array}{l}\text { Turno de } \\
\text { trabalho }\end{array}$ & $\begin{array}{c}\text { Diurno } \\
\text { Noturno } \\
\text { Ambos }\end{array}$ & $\begin{array}{l}29(35,3) \\
39(47,5) \\
14(17,0)\end{array}$ & $\begin{array}{l}23(31,5) \\
27(36,9) \\
23(31,5)\end{array}$ & 0,102 \\
\hline
\end{tabular}




\subsection{Correlação entre a cultura e o clima organizacional nos profissionais do serviço de emergência}

Na tabela 11 que segue, apresentam-se os resultados do teste de correlação de Spearman quanto as variáveis da cultura e o clima organizacional nos profissionais do serviço de emergência.

Os resultados evidenciaram que nas análises entre cultura e clima organizacional houve correlação estatisticamente significativa entre o fator 1 - "Profissionalismo cooperativo", 4 "Satisfação e bem-estar dos empregados", 5 - "Práticas de integração externa" e 6 - "Práticas de recompensa e treinamento" da cultura organizacional com todos os fatores do clima organizacional (Apoio da chefia e da organização, Recompensa, Conforto físico, Controle/Pressão e Coesão entre colegas), todas com um nível de significância abaixo de 0,01.

Considerando-se a cultura organizacional relacionada ao profissionalismo cooperativo os resultados evidenciaram que quanto maior o profissionalismo cooperativo melhor será o clima organizacional relacionado ao apoio da chefia e da organização (Spearman CC=0,765*, $\mathrm{p}=0,000$ ), Recompensa Spearman $\mathrm{CC}=0,765^{*}, \mathrm{p}=0,000$, Conforto físico Spearman $\mathrm{CC}=0,765^{*}$, p=0,000, Controle/Pressão e Coesão entre colegas Spearman CC=0,765*, p=0,000.

Considerando-se a cultura organizacional relacionada à rigidez na estrutura hierárquica de poder os resultados evidenciaram que quanto maior está a rigidez menor o conforto físico (Spearmen CC-0 $\left.=-0,162^{\prime} \mathrm{p}=0,045\right)$. Por outro lado quanto maior esta rigidez maior também o clima relacionado a controle e pressão ( $\mathrm{CC}=0,343$ ' $\mathrm{p}=0,000$ ).

Considerando-se a cultura organizacional relacionada Profissionalismo competitivo e individualista os resultados evidenciaram que quanto maior a Recompensa melhor será o clima organizacional relacionado a recompensa da organização (Spearman $\mathrm{CC}=0,237^{*}, \mathrm{p}=0,003$ ), Controle/ pressão Spearman $\mathrm{CC}=0,243^{*}, \mathrm{p}=0,002$.

Já na correlação entre cultura organizacional fator 4- "Satisfação e bem-estar dos empregados" e clima organizacional, foi possível notar forte correlação entre todos os fatores do clima organizacional, "Apoio da chefia e da organização" (Spearman CC=0,564*, p=0,000), "Recompensa" Spearman CC=0,512*, $\mathrm{p}=0,000$, "Conforto físico" Spearman CC=0, ,339*, $\mathrm{p}=0,000$, “Controle/Pressão" Spearman $\mathrm{CC}=0,190^{*}, \mathrm{p}=0,019$ e "Coesão entre colegas" Spearman $\mathrm{CC}=0,398^{*}, \mathrm{p}=0,000$. 
Observa-se na correlação entre cultura organizacional fator 5 "Práticas de integração externa" e clima organizacional, foi possível notar forte correlação entre todos os fatores do clima organizacional, "Apoio da chefia e da organização" (Spearman CC=0,455*, p=0,000), "Recompensa" Spearman $\mathrm{CC}=0,320^{*} * \mathrm{p}=0,000$, "Conforto físico" Spearman $\mathrm{CC}=0,217^{*}$, $\mathrm{p}=0,007, \quad$ "Controle/Pressão" Spearman $\quad \mathrm{CC}=0,412 \quad \mathrm{p}=0,000$ e "Coesão entre colegas" Spearman $\mathrm{CC}=0,322^{*}, \mathrm{p}=0,000$.

Considera-se na correlação entre cultura organizacional fator 6 "Práticas de recompensa e treinamento" e clima organizacional, foi possível notar forte correlação entre todos os fatores do clima organizacional, "Apoio da chefia e da organização" (Spearman $\mathrm{CC}=0,436 *, \mathrm{p}=0,000)$, "Recompensa" Spearman $\mathrm{CC}=0,396^{*}$, $\mathrm{p}=0,000$, "Conforto físico" Spearman $\quad \mathrm{CC}=0,217^{*}, \quad \mathrm{p}=0,007$, “Controle/Pressão" Spearman $\quad \mathrm{CC}=0,197 \quad \mathrm{p}=0,015$ e "Coesão entre colegas" Spearman CC=0,254", p=0,002.

Por fim nota-se correlação entre cultura organizacional fator 7 "Práticas de relacionamento interpessoal" e clima organizacional, foi possível notar forte correlação entre todos os fatores do clima organizacional, "Apoio da chefia e da organização" (Spearman $\mathrm{CC}=0,579 *, \mathrm{p}=0,000)$, "Recompensa" Spearman $\mathrm{CC}=0,499^{*} * \mathrm{p}=0,000$, "Conforto físico" Spearman $\mathrm{CC}=0,288^{*}, \mathrm{p}=0,000$ e "Coesão entre colegas" Spearman $\mathrm{CC}=0,432^{*}, \mathrm{p}=0,000$. 
Tabela 11: Correlação da cultura (IBACO) e clima (ECO) organizacional, Ribeirão Preto, SP, 2018.

\begin{tabular}{|c|c|c|c|c|c|c|}
\hline \multirow{2}{*}{$\begin{array}{c}\text { Fatores da Cultura } \\
\text { organizacional }\end{array}$} & \multirow{2}{*}{$\begin{array}{l}\text { Teste de } \\
\text { correlação de } \\
\text { Spearman }\end{array}$} & \multicolumn{5}{|c|}{ Fatores do Clima organizacional } \\
\hline & & $\begin{array}{c}1 \text { - apoio da chefia e } \\
\text { da organização }\end{array}$ & 2 - Recompensa & $\begin{array}{l}3 \text { - Conforto } \\
\text { físico }\end{array}$ & $\begin{array}{c}4 \text { - Controle / } \\
\text { pressão }\end{array}$ & $\begin{array}{c}5 \text { - Coesão } \\
\text { entre colegas }\end{array}$ \\
\hline \multirow[t]{3}{*}{$\begin{array}{l}1 \text {-Profissionalismo } \\
\text { cooperativo }\end{array}$} & $\begin{array}{l}\text { Coeficiente de } \\
\text { Correlação }\end{array}$ &, $765 *$ &, $596^{*}$ &, $445^{*}$ &, $314^{*}$ &, $516^{*}$ \\
\hline & $\mathrm{P}$ & $\mathbf{0 , 0 0 0}$ & $\mathbf{0 , 0 0 0}$ & $\mathbf{0 , 0 0 0}$ & $\mathbf{0 , 0 0 0}$ & $\mathbf{0 , 0 0 0}$ \\
\hline & $\mathrm{N}$ & 155 & 155 & 155 & 154 & 154 \\
\hline \multirow{3}{*}{$\begin{array}{l}2 \text { - Rigidez na } \\
\text { estrutura } \\
\text { hierárquica de } \\
\text { poder }\end{array}$} & $\begin{array}{l}\text { Coeficiente de } \\
\text { Correlação }\end{array}$ & $-0,060$ & $-0,038$ &,$- 162^{*}$ & , $343^{*}$ & $-0,074$ \\
\hline & $\mathrm{P}$ & 0,462 & 0,645 & 0,045 & $\mathbf{0 , 0 0 0}$ & 0,365 \\
\hline & $\mathrm{N}$ & 153 & 153 & 153 & 152 & 152 \\
\hline \multirow{3}{*}{$\begin{array}{l}3 \text { - Profissionalismo } \\
\text { competitivo e } \\
\text { individualista }\end{array}$} & $\begin{array}{l}\text { Coeficiente de } \\
\text { Correlação }\end{array}$ & 0,147 & $237^{*}$ & 0,065 & $243^{*}$ & 0,116 \\
\hline & $\mathrm{P}$ & 0,069 & 0,003 & 0,423 & 0,002 & 0,152 \\
\hline & $\mathrm{N}$ & 154 & 154 & 154 & 153 & 153 \\
\hline \multirow{3}{*}{$\begin{array}{l}4 \text { - Satisfação e } \\
\text { bem-estar dos } \\
\text { empregados }\end{array}$} & $\begin{array}{c}\text { Coeficiente de } \\
\text { Correlação }\end{array}$ &, $564^{*}$ &, $512^{*}$ &, $339^{*}$ & $190^{*}$ &, $398^{*}$ \\
\hline & $\mathrm{P}$ & 0,000 & 0,000 & $\mathbf{0 , 0 0 0}$ & 0,019 & $\mathbf{0 , 0 0 0}$ \\
\hline & $\mathrm{N}$ & 153 & 153 & 153 & 152 & 152 \\
\hline \multirow[t]{3}{*}{$\begin{array}{l}5 \text { - Práticas de } \\
\text { integração externa }\end{array}$} & $\begin{array}{l}\text { Coeficiente de } \\
\text { Correlação }\end{array}$ &, $455^{*}$ &, $320^{*}$ &, $427^{*}$ &, $412^{*}$ &, $322^{*}$ \\
\hline & $\mathrm{P}$ & $\mathbf{0 , 0 0 0}$ & 0,000 & $\mathbf{0 , 0 0 0}$ & $\mathbf{0 , 0 0 0}$ & 0,000 \\
\hline & $\mathrm{N}$ & 154 & 154 & 154 & 153 & 153 \\
\hline \multirow{3}{*}{$\begin{array}{l}6 \text { - Práticas de } \\
\text { recompensa e } \\
\text { treinamento }\end{array}$} & $\begin{array}{l}\text { Coeficiente de } \\
\text { Correlação }\end{array}$ & $436^{* * *}$ &, $396^{* * *}$ &, $217^{* * *}$ & $197^{*}$ &, $254^{*}$ \\
\hline & $\mathrm{P}$ & 0,000 & 0,000 & 0,007 & 0,015 & 0,002 \\
\hline & $\mathrm{N}$ & 153 & 153 & 153 & 152 & 152 \\
\hline \multirow{3}{*}{$\begin{array}{l}7 \text { - Práticas de } \\
\text { relacionamento } \\
\text { interpessoal }\end{array}$} & $\begin{array}{c}\text { Coeficiente de } \\
\text { Correlação }\end{array}$ &, $579^{*}$ &, $499^{*}$ &, $288^{*}$ & 0,109 &, $432^{*}$ \\
\hline & $\mathrm{P}$ & $\mathbf{0 , 0 0 0}$ & $\mathbf{0 , 0 0 0}$ & $\mathbf{0 , 0 0 0}$ & 0,182 & 0,000 \\
\hline & $\mathrm{N}$ & 153 & 153 & 153 & 152 & 152 \\
\hline
\end{tabular}

$\mathrm{P}=$ nível de significância; * destaque para correlação nível de significativa $\mathrm{p} \leq 0,05$.

Observa-se também a correlação entre o fator 3 "Profissionalismo competitivo e individualista" da cultura organizacional e os fatores 2 "Recompensa" (p 0,003) e 4 "Controle/Pressão" (p 0,002) do clima organizacional.

Por fim, no fator 9 "Práticas de relacionamento interpessoal" houveram correlações exceto no fator 4 "Controle/Pressão" do clima organizacional, os demais fatores houveram com um nível de significância abaixo de 0,01.

\subsection{Variáveis preditoras do estresse atual relacionadas aos profissionais do serviço de emergência}

Na tabela 12 é possível observar a relação do estresse com as variáveis: sexo (p 0,017; $\operatorname{Exp}(B) 2,766)$, vínculo empregatício (p 0,049; $\operatorname{Exp}(B)$ 1,403) e o fator 2 "Recompensa" da escala de clima organizacional (p 0,002; $\operatorname{Exp}(B) 0,396)$. 
Verificou-se assim que as mulheres têm 2,77 vezes mais chance de apresentar estresse com relação aos homens. E que para cada vínculo empregatício que os profissionais apresentaram, eles tinham 1,4 vezes mais chances de apresentar estresse.

Por fim observa-se que a cada ponto a mais obtido no escore do fator 2 "Recompensa" da escala de clima organizacional é esperada uma redução de 60,4\% (1-0.396) na chance de ocorrência de estresse.

Tabela 12: Variáveis preditoras do estresse, Ribeirão Preto, SP, 2018.

\begin{tabular}{c|l|c|c|c}
\multicolumn{2}{c}{ VARIÁVEIS DA EQUAÇÃo } & P & EXP(B) & $\begin{array}{c}\text { EXP(B) } \\
\text { IC 95\% }\end{array}$ \\
\hline \multirow{2}{*}{ PASSO 1 } & Fator 2 - Recompensa (ECO) & $0,001^{*}$ & 0,370 & $0,210-0,651$ \\
\hline \multirow{2}{*}{ PASSO 2 } & Sexo & $0,043^{*}$ & 2,248 & $1,024-4,936$ \\
\cline { 2 - 5 } & Fator 2 - Recompensa (ECO) & $0,001^{*}$ & 0,394 & $0,223-0,696$ \\
\hline \multirow{2}{*}{ PASSO 3 } & Sexo & $0,017^{*}$ & 2,766 & $1,201-6,371$ \\
\cline { 2 - 5 } & Vínculos Empregatícios & $0,049^{*}$ & 1,403 & $1,001-1,968$ \\
\cline { 2 - 5 } & Fator 2 - Recompensa (ECO) & $0,002^{*}$ & 0,396 & $0,222-0,706$ \\
\hline
\end{tabular}

$\mathrm{IC}=$ intervalo de confiança; $\mathrm{p}=$ nível de significância, ${ }^{*} \mathrm{p} \leq 0,05$.

\subsection{Síntese dos resultados mais importantes}

As análises estatísticas permitiram inferir que a cultura e o clima organizacional estão relacionadas ao estresse atual entre os profissionais da saúde de um serviço de emergência. Conforme representado na figura que segue. 
Figura 1: Cultura e clima organizacional e sua relação com o estresse entre profissionais de um serviço de emergência. Ribeirão Preto, 2018.

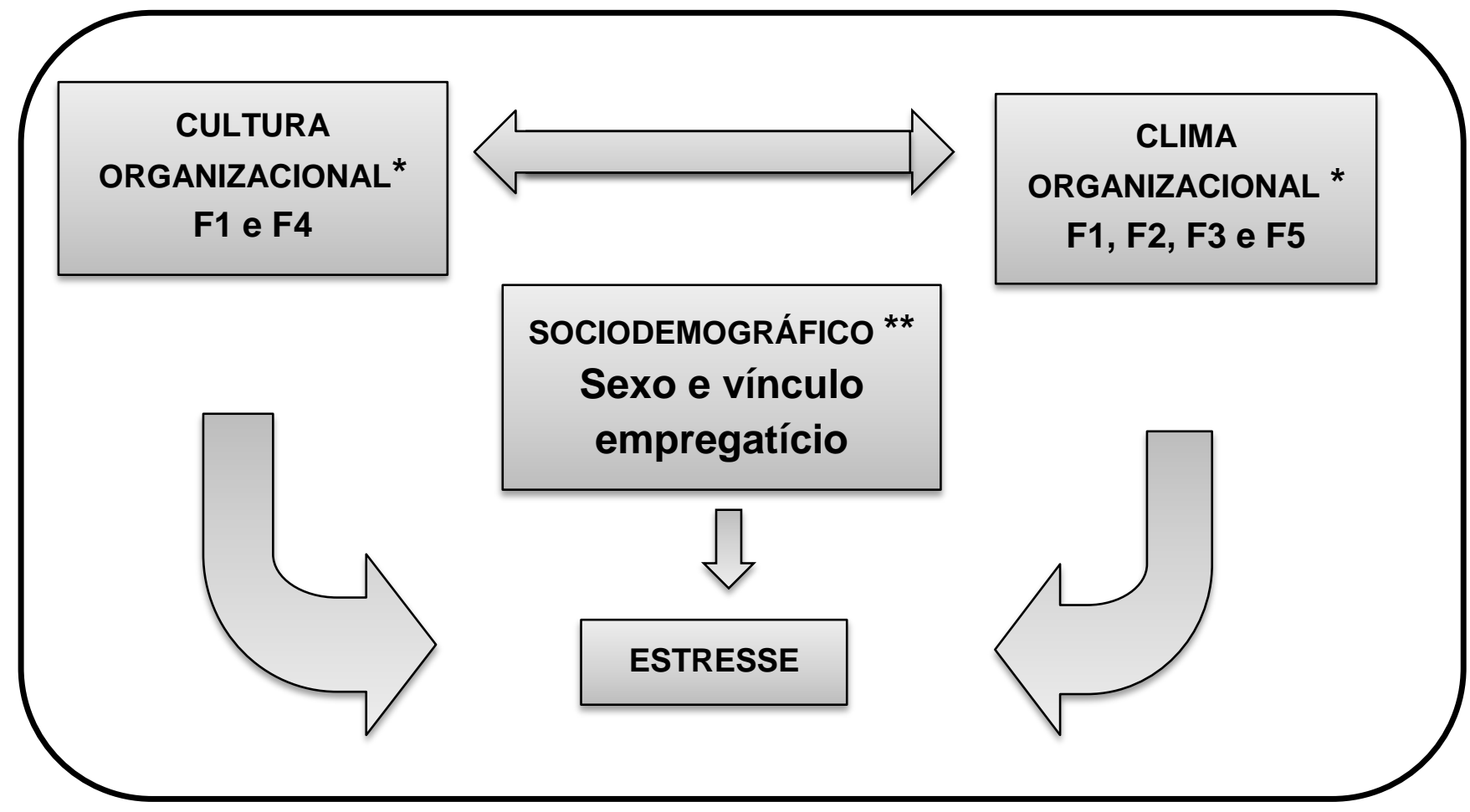

*mann Whitney; **regressão logística 


\section{Discussão}

Este estudo atingiu todos os objetivos propostos e a hipótese nula de que não há relação entre clima, cultura organizacional e estresse atual foi rejeitada. Isto porque, os resultados evidenciaram que a cultura e o clima organizacional influenciaram o estresse atual em diferentes aspectos conforme será discutido a seguir.

Os resultados do presente estudo comprovaram a presença de estresse na maioria dos profissionais de saúde de um serviço de emergência. Sabe-se que a prevalência do estresse vem aumentando cada vez mais, no mundo do trabalho, e que os profissionais da saúde estão cada vez mais susceptíveis as várias fases do estresse. Embora a grande parte das pessoas acredite que o estresse é negativo, geralmente associado a sensações de desconfortos e relacionados a prejuízos, sabe-se que o estresse é um fenômeno dinâmico, complexo e necessário à sobrevivência. Por isso, não deve ser visto de forma única, descontextualizada e em uma condição estática.

Para Selye (1936) o estresse é um processo adaptativo, presente na vida de todas as pessoas e que pode levar ou não ao adoecimento. No presente estudo, além da quase a metade dos profissionais estarem com estresse, chama a atenção a predominância dos profissionais nas fases de resistência $(76,7 \%)$ e quase-exaustão (17,8\%). O que evidencia que esses profissionais já estavam em fases que tem como uma das consequências o adoecimento.

Em um estudo realizado por Mello (2018) para investigar a cultura organizacional entre enfermeiros que atuavam em unidades de terapia intensiva, a taxa de estresse era 56,7\%. O estresse nestes profissionais foi maior que no presente estudo, mas as fases predominantes eram semelhantes, havendo uma maior população na fase de resistência, possuindo assim, consequências na saúde desses profissionais, como visto anteriormente.

Estudo de Ferrareze (2006), que ivetigava a ocorrência de estresse entre enfermeiros que atuam na assistência em Unidades de Cuidados Intensivos - evidenciou que na fase de resistência - persiste o desgaste do estado de alerta. O organismo continua buscando ajustar-se a situação estressante, mobilizando energia, o que traz algumas consequências como: aumento do córtex da suprarrenal, atrofias de algumas estruturas relacionadas às células sanguíneas, ulceração do 
aparelho digestivo, irritabilidade, insônia, mudança de humor, diminuição do desejo sexual, entre outros.

Estudo de Miquelim (2004), que ivetigava o estresse entre profissionais da enfermagem que atuam com pacientes portadores de HVI-AIDS - evidenciou que na Fase de quase-exaustão o organismo está enfraquecido e não consegue se adaptar ou resistir ao estressor. As doenças começam a aparecer, tais como: herpes simples, psoríase, picos de hipertensão e diabetes em indivíduos geneticamente predispostos. Quando o estressor permanece atuante por muito tempo, ou quando muitas fontes de estresse ocorrem simultaneamente, a reação do organismo progride para a fase de exaustão.

O estresse está ligado à vulnerabilidade (predisposição para reagir intensamente, através de reações psicológicas e físicas frente a situações estressantes) do indivíduo. Todo ser humano está susceptível a vulneráveis ou desfavoráveis, porém a vulnerabilidade podem ser inatos (relacionado com a genética pessoal, representando o ambiente interno - neurofisiologia do organismo) e adquiridos (sofre influencia do ambiente externo, através de doenças físicas, experiências e relacionamentos). Neste sentido, pode-se inferir que o ambiente de trabalho influencia de forma direta na presença ou ausência de estresse no individual, sabe-se que a temática estresse possui muitas formas de avaliação uma delas é no ambiente de trabalho, no qual essa pesquisa mostra a influencia do ambiente de trabalho na influencia do estresse entre os profissionais da saúde de um serviço de emergência.

O trabalho influencia na qualidade de vida, pois é ele que motiva e gratifica, exigindo concentração, raciocínio e desgaste físico e/ou mental. No trabalho de Oliveira (2013), uma revisão bibliográfica que teve como objetivo identificar a viabilidade de reduzir fatores estressantes no ambiente de trabalho, o estudo evidenciou que o estresse é quase sempre visto como um fator negativo na vida das pessoas e que prejudica o desempenho do individuo, é importante compreender que em determinados níveis o estresse é necessário ao organismo, pois colabora com o bom desempenho das funções orgânicas e psíquicas. O trabalho na área da saúde é visto como um grupo de profissões desgastante, pois o ambiente de trabalho oferece um constante contato com doenças, colocando esses profissionais em risco de natureza física, química, biológica e psíquica, também há uma complexidade relacionada aos diversos procedimentos, responsabilidades, tomada de decisão e turno de trabalho, todos esses fatores relacionam-se com a influência do estresse no ambiente de trabalho, principalmente em 
ambientes de emergência, levando a frequentes situações de estresse (OLIVEIRA, et. al., 2013). Destaca-se a relação do trabalho de Oliveira (2013) com o presente estudo, pois ambos identificam o ambiente de trabalho um local com fortes influências ao estresse.

Além disso, estudos evidenciam que o salário, quantidade inadequada de profissionais nos setores, chefia, relacionamento com os colegas da área da saúde, falta de espaço no trabalho para discutir as experiências, tanto as positivas como as negativas, falta de material necessário ao trabalho, ter um prazo curto para cumprir ordens, falta de tempo para si mesmo, trabalhar com pessoas despreparadas e sentir desgaste emocional no local de trabalho, torna o ambiente de trabalho um local com fortes influências ao estresse (PASSOS, 2010; ATAÍDE, et. al., 2016; dos REIS SEMEDO, 2018).

Sabe-se que os profissionais de saúde estão vulneráveis ao estresse relacionado ao trabalho, uma vez que sua atividade profissional exige contato intenso com pessoas e enfrentamento de inúmeras situações de estresse. Os profissionais que atuam em ambientes hospitalares estão susceptíveis a sentimentos como: piedade, compaixão, amor, culpa, ansiedade, ódio, ressentimento. Os serviços de emergências são vistos como ambiente estressor, devido ao trabalho normatizado, fragmentado, com excessiva responsabilidade, rotatividade de turnos e cobrança por constante ampliação de conhecimentos. Os profissionais nos serviços de emergência lidam com situações que exigem conhecimento, autocontrole e eficiência ao prestarem assistência ao paciente, a fim de não cometerem erros.

O presente estudo apontou que os profissionais da saúde de serviços de emergência lidam constantemente com um ambiente tenso, que exige muito conhecimento, agilidade e calma, mas que muitas vezes o próprio local de trabalho não oferta recursos necessários para minimizar esse desgaste mental e físico que este ambiente precisa. Dessa forma o estresse foi evidenciado neste estudo sob a influência da cultura e o clima organizacional do local estudo.

De acordo com as análises dos resultados obtidos, observou-se uma prevalência de uma cultura organizacional enrijecida na estrutura hierárquica de poder e um profissionalismo competitivo (média 3,026) e individualismo entre os trabalhadores na instituição (média 2,286) em relação com o estresse atual. Sabe-se que a cultura organizacional é um conjunto de normas, mitos, crenças, valores, padrões e hábitos, ou seja, um conjunto de pressupostos básicos definidos por cada grupo, no qual proporciona formas de lidar com problemas e adaptações a eles. Dentro dessa perspectiva, observa-se que na amostra estudada há uma certa dificuldade no 
desenvolvimento de práticas de trabalho em equipe, possibilitando dessa forma uma existência de rigidez hierárquica e centralização de poder na instituição, dificultando o ambiente profissional e tornando um ambiente com maiores fatores estressores.

Por outro lado, o clima organizacional é capaz de avaliar liderança, interações humanas e reconhecimento. Dessa forma, climas ruins sugerem lideranças ruins, interações humanas ruins, valorização profissional inadequada e espaço físico ruim, consequentemente é uma variável que influi na qualidade, produtividade e rentabilidade das organizações.

Importante destacar também que entre os profissionais com estresse a percepção do clima organizacional foi mais negativa. Climas negativos mostram que há uma insatisfação entre os profissionais deste local, podendo ser relacionada a chefia ou remuneração ou conforto físico ou relacionamento entre os profissionais ou controle e pressão exercido pela empresa/chefia nos profissionais, dessa forma seria importante uma aproximação da chefia com os profissionais para melhoria desse desajuste, tornando assim um ambiente mais positivo.

Com relação à literatura, estressores físicos, sociais e liderança são variáveis preditoras de estresse (MELO, 2016). Entre os profissionais de saúde dos serviços de emergência investigados no presente estudo, os fatores relacionados à remuneração/recompensa apresentaram alterações negativas no resultado analisado. Neste contexto, sabe-se que a insatisfação com o salário atual e que a remuneração não é tão adequada a função exercida e isso demonstrou relação com o estresse, tornando possíveis adoecimentos em relação à remuneração/recompensa.

No presente estudo foi possível evidenciar que a cultura e o clima organizacional estão relacionados entre si, mostrando que uma exerce influência sobre a outra, tornando a cultura organizacional um fator mais enrijecido e pregresso no local de trabalho. Já o clima algo mais momentâneo, representando como está o ambiente de trabalho no momento atual. Embora a cultura não tenha se evidenciado com preditor do estresse atual, sua influencia no clima e sua relação com o estresse explicam, em grande parte, os resultados obtidos no presente estudo.

Dentro desse estudo foi possível verificar a forte influência da cultura em relação ao clima organizacional, no que se refere a cultura enrijecida e um clima ruim observados, bem como sua relação com o estresse. Segundo Pereira (2014) fato de não conseguir desligar-se dos contextos relacionados ao trabalho, ter uma vida corrida, trabalhando excessivamente e a realização de varias coisas ao mesmo tempo, são fatores de tensão excessiva no trabalho. Tais achados apresentam semelhança com o presente trabalho, pois pode-se inferir que esta tensão está 
relacionada ao ambiente de trabalho influenciou a ocorrência de estresse atual nos profissionais estudados. O que se comprovou através do clima organizacional e também da quantidade de vínculo empregatício que cada profissional estudado possuía.

Por fim, cabe destacar a maior vulnerabilidade das mulheres na incidência de estresse, dado que corrobora com outros estudos nacionais e internacionais com profissionais de saúde (LIPP, 2010; COSTA, et. al., 2015).

Estudar a manifestação do estresse, cultura organizacional e clima organizacional em profissionais de saúde de um serviço de emergência é relevante porque evidencia de forma mais objetiva o impacto destes fenômenos na saúde destas pessoas, o que também indiretamente impacta a assistência a saúde. Mais estudos na área podem contribuir para o desenvolvimento de internações voltadas a saúde destes trabalhadores.

Neste estudo, foram utilizados instrumentos validados e detalhados que possibilitaram compreensão ampla dos fatores que podem determinar a ocorrência dos fenômenos investigados. Tal opção considerou os instrumentos disponíveis e sua abrangência. Devido ao grande número de itens nos questionários, alguns participantes queixaram-se da extensão dos questionários. Assim, para a realização de futuros estudos é importante considerar outros instrumentos relevantes para investigar tais fenômenos. Estudos qualitativos, longitudinais e com diferentes desenhos podem contribuir com diferentes evidências e contribuições para a área.

Embora os resultados deste estudo sejam importantes e contribuam para a área de estudo, ressalta-se, por fim, a inexistência de trabalhos semelhantes o que limitou a comparação, ampliação ou generalização dos resultados. 


\section{CONCLUSÕES FINAIS}

O presente estudo possibilitou concluir a influencia da cultura e clima organizacional de uma organização de saúde hospitalar de emergência e sua relação com a prevalência de estresse. Também identificou a ligação entre cultura e clima organizacional, mostrando a influência da cultura sobre o clima organizacional.

A cultura e clima organizacional são temáticas de extrema importância na identificação de problemas, tais quais, insatisfações/inadequações relacionadas a estrutura física do ambiente, remuneração, chefias, enfim, essas temáticas identificam o ambiente de trabalho relacionados aos

profissionais nele atuante. Dessa forma, estudar a cultura e o clima organizacional, faz com que possibilite uma identificação e posteriormente adequação do ambiente de trabalho.

Outra temática importante abordada no presente estudo foi o estresse. O estresse é de suma importância, pois afeta uma alta porcentagem da população mundial, por ser algo comum, ele ainda é uma doença subestimada e como consequência a ausência no tratamento e prevenções, dessa forma o presente estudo se mostra de grande importância, pois apresenta fatores que influenciam a presença do estresse entre profissionais atuantes na área da saúde.

Em suma, o presente estudo pode relacionar questões voltadas para um ambiente de trabalho com profissionais da saúde atuantes em um serviço de emergência. A escassez de estudos voltados para a cultura e o clima organizacional e sua relação com estresse, tornou o presente estudo importante para a área literária, dessa forma permitindo a continuidade de novos estudos nas temáticas apresentadas.

Deste modo, o presente estudo teve por finalidade ampliar a compreensão a cerca da cultura e do clima organizacional no contexto do cuidado em serviços de emergência e seu impacto na ocorrência do estresse entre profissionais de saúde. Trata-se de uma proposta condizente com a atualidade, o cuidado na linha de emergência, notadamente em relação à saúde dos trabalhadores desta área. 
9. REFERÊNCIAS 


\section{REFERÊNCIAS}

ADRIAENSSENS, J.; DE GUCHT, V.; MAES, S. Determinants and prevalence of burnout in emergency nurses: a systematic review of 25 years of research. Int J Nurs Stud, v.52, n.2, p.649-661, 2015.

ALMEIDA FILHO, N. O que é saúde. Fiocruz, Rio de Janeiro. 2011.

ALMEIDA, L.G.R.S.; JARDIM, M.G.; FRANCO, E.C.D. O cuidar do idoso com Alzheimer: sentimentos e experiências vivenciados por seus cuidadores. Capa, v.4, n.2, 2014.

ALVES, M.; GODOY, S. C. B.; SANTANA, D. .M. Motivos de licenças médicas em um hospital de urgência-emergência. Rev. Bras. Enferm, v.59, n.2, 2006.

ALVESSON, M.. Cultural perspectives on organizations. Cambridge: Cambridge University Press, 1993.

ASHKANASY, N.P.; WILDEROM, C.P.M.; PETERSON, M.F. Handbook of organizational culture and climate. California: Sage Pub, 2000.

ATAÍDE, M.; VINHÁTICO, P.; ANDRADE, S.; GARCIA, C.P.C. Fatores determinantes da síndrome de Bournout em enfermeiros na Unidade de Terapia Intensiva. Repositório institucional - Escola Bahiana de medicina e saúde pública, v.1, n.1, 2016.

AVElinO, F. V. S. D.; LEITE, A. R. F.; FERNANDES, M. A.; AVELINO, F. P. D.; MADEIRA, M. Z. A.; SOUSA, L. E. N. Stress in nurses sector of emergency and emergency. Rev. Enferm. UFPI, v.2, n.3, p.4-10, 2013.

BANNAY, R. A.; BOHM, M.; HUSAIN, A. Heart ate differentiates urgency and emergency in hypertensive crisis. Clin. Res. Cardiol., v. 102, n.8, p.593-598, 2013.

BARRoS, A. J. P.; LEHFELD, N. A. S. Projeto de Pesquisa: propostas metodológicas. Petrópolis: Vozes, 1990.

BARROS, B.T. Fusões e aquisições no Brasil - Entendendo as razões dos sucessos e fracassos. São Paulo, Atlas 2003.

BATISTA, K.M.; BIANCHI, E.R.F. Estresse do enfermeiro em unidade de emergência. Rev LatinoAmericada de Enfermagem, v.14, n.4, p. 534-539, 2006.

BENDASSOLLI, P.F.; BORGES-ANDRADE, J.E. Dicionário de psicologia do trabalho e das organizações. São Paulo, Casapsi Livraria e Editora Ltda, 2015. 
BENTLEY, M.A.; CRAWFORD, M.; WILKINS, J.R.; FERNANDEZ, A.R.; STUDNEK, J. An Assessment of Depression, Anxiety, and Stress Among Nationally Certified EMS Professionals. Prehospital Emergency Care, v.17, n.3, p.330-338, 2013.

BEZERRA, F. N.; SILVA, T. M.; RAMOS, V. P. Estresse ocupacional dos enfermeiros de urgência e emergência: Revisão Integrativa da Literatura. Acta Paul. Enferm., v.25, n.2, p. 151-156, 2012.

BORDALO, A.A. Estudo transversal e/ou longitudinal. Revista Paraense de Medicina, v.20, n.4, 2006.

BRASIL. Conselho Nacional em Saúde. Resolução n 466/12, de dezembro de 2012.

BRASIL. Ministério da Saúde. Portaria $\mathbf{N}^{\mathbf{2}}$ 2048, de 5 de novembro de 2002. Brasília: Ministério da Saúde, 2002.

BRASIL. Ministério da Saúde. Urgência e Emergência. Brasília: Ministério da Saúde, 2001.

CANDEIAS, N.M.F.; ABUJAMRA, A.M.D.; SABBAG, S.N. Stress em atendentes de enfermagem. Rev. bras. saúde ocup 75, vol. 20, pp. 38-44, 1992.

CHIAVENATO, I. Introdução a Teoria Geral Da Administração. Ed. Elsevier, São Paulo, 2004.

CHROUSOS, G.P.; LORIAUX, D.L.; GOLD, P.W. Mechanisms of Physical and Emotional Stress. Advances in Experimental Medicine and Biology. v.245, 1988.

CHROUSOS, G.P.; GOLD, P.W. The concepts of stress and stress system disorders. Overview of physical and behavioral homeostasis. JAMA, v. 267, n.4, p.1244-1252, 1992.

CODA, R. Estudo sobre clima organizacional traz contribuição para aperfeiçoamento de pesquisa na área de RH. In: Boletim Administração em Pauta, suplemento da Revista de Administração, n. 75, 1993.

Conselho Federal de Medicina. Resolução CFM n. 145/95. Conselho Federal de Medicina, 1995.

COSTA, F. D.; TEO, C. R. P. A.; ALMEIDA, J. S. Vulnerabilidade ao estresse e alimentação: um estudo no contexto do trabalho. Sci. med; v.25, n.2, 2015.

DAL PAI, D.; LAUTERT, L. O trabalho em urgência e emergência e a relação com a saúde das profissionais de enfermagem. Rev. Latino-am Enfermagem, v.16, n.3, 2008.

DEJOURS, C.; ABDOUCHELI, E.; JAYET, C. Psicodinâmica do trabalho: contribuições da Escola Dejouriana à análise da relação prazer, sofrimento e trabalho. São Paulo, Atlas, 1994. 
DENZIN, N.K.; LINCOLN, Y. S. Handbook of Qualitative Research. Thousand Oaks: Sage, 2005.

DUFFY, E.; AVALOS, G.; DOWLING, M. Secondary traumatic stress among emergency nurses: a cross-sectional study. International Emergency Nursing, v.23, n. 2, p.53- 58, 2015.

ETKIN, J. R. Identidad de las organizaciones: invariância y cambio. Ed. Paidós, Buenos Aires, 2005.

FARO, A.; PEREIRA,M.E. Estresse: Revisão Narrativa da Evolução Conceitual, Perspetivas Teóricas e Metodológicas. Psic., Saúde e Doenças, v.14, n.1, 2013.

FERNANDES, J. C.; PORTELA, L. F.; ROTENBERG, L.; GRIEP, R. H. Jornada de trabalho e comportamento de saúde entre enfermeiros de hospitais públicos. Rev. Latino-Americana de Enfermagem, v.21, n.5, p.1-8, 2013.

FERNANDES, M. A.; SOUSA, F. K.; SANTOS, J. S.; RODRIGUES, J. A.; MARZIALE, M. H. P. Burnout syndrome in nursing professionals of emergency medical care service. Tese de Mestrado, Escola de Enfermagem de Ribeirão Preto, 2012.

FERRAREZE, M. V. G.; FERREIRA, V.; CARVALHO, A. M. P..Percepção do estresse entre enfermeiros que atuam em Terapia Intensiva. Acta Paul Enferm, v.19, n.3, pp.310-15, 2006.

FERREIRA, M. C.; ASSMAR, E. M. L. Fontes ambientais de estresse ocupacional e burnout: tendências tradicionais e recentes e de investigação. Estresse e Cultura Organizacional (pp. 21 -75). São Paulo: Casa do Psicólogo, 2008

FERREIRA, M.C.; ASSMAR, E.M.L.; ESTOL, K.M.F.; HELENA, M.C.C.C.; FIGUEIREDO, M.C. Desenvolvimento de um instrumento brasileiro para avaliação da cultura organizacional. Estudos de Psicologia, v.7, n.2, p.271-280, 2002.

FIGUEIREDO, N.M.A. Métodos e Metodologia na Pesquisa Científica. Difusão Editora, 2004. FLEURY, M. T. L.; FISCHER, R. M. Cultura e poder nas organizações. Ed. Atlas, 1989.

FOREHAND, G. A.,;GILMER, H. B. Environmental variation in studies of organizational behavior. Psychological Bulletin, n. 62, v. 6, p.361-382, 1964.

FREITAS, M. E. Cultura organizacional: evolução e crítica. Cengage Learning, São Paulo, 2007.

GHERARDI-DONATO, E.C.S.; CARDOSO, L.; TEIXEIRA, C.A.B.; PEREIRA, S.S.; REISDORFER, E. Associação entre depressão e estresse laboral em profissionais de enfermagem de nível médio Rev. Latino-Am. Enfermagem,v.23, n.4, p.733-40, 2015. 
GIL, A.C. Como elaborar projetos de pesquisa. 4. ed, Atlas, São Paulo, 2002.

GUILLÉN GESTOSO, C. La importancia del estrés laboral en el mundo actual. Ateneo: revista cultural del Ateneo de Cádiz, v. 5, p. 84-95, 2005.

HAPPELL, B.; DWYER, T.; REID-SEARL, K.; BURKE， K.J.; CAPERCHIONE, C.M.; GASKIN, C.J. Nurses and stress: recognizing causes and seeking solutions. J Nurs Manag. v.21, n.4, pp.638-47, 2013.

HAYATI, D; KARAMI, E.; SLEE, B. Combining qualitative and quantitative methods in the measurement of rural poverty. Social Indicators Research, v.75, p.361-394, Springer, 2006.

HETTI, L.B.E; BERNARDES, A.; GABRIEL, C.S.; FORTUNA, C.M.; MAZIERO, V.G. Educação permanente/continuada como estratégias de gestão no serviço de atendimento móvel de urgência. Rev. Eletr. Enf., v.15 n.4, 2013.

HOFSTEDE, A. H. M.; VERHOEF, T. F. On the feasibility of situational method engineering. Elsevier, v.22, p. 401-422, 1997.

Instituto Brasileiro de Geografia e Estatística (IBGE). Estimativa populacional 2012. IBGE. Disponível em: http://cidades.ibge.gov.br/xtras/perfil.php?codmun=354340

JACQUES, E. The Changing culture of a factory. Tavistock Publications Limites, 1951.

KINPARA, D. I.; LAROS, J. A. Clima organizacional: análise fatorial confirmatória de modelos de mensuração concorrentes. Revista Psicologia, v.30, n.1, 2014.

KOLB, D. A. Psicologia Organizacional: uma abordagem vivencial. São Paulo, Atlas, 1986.

KREIN, J.D. As transformações no mundo do trabalho e as tendências das relações de trabalho na primeira década do século XXI no brasil. Revista NECAT, v. 2, n. 3, pp. 6-25, 2013.

LIMA, L.C.; AMORIM, W.A.C.; FISCHER, A.L. Da racionalidade instrumental para a substantiva: explorando possibilidades da gestão de clima organizacional. CAPA, v.5, n.1, 2015.

LIMA-COSTA, M.F.; BARRETO, S.M. Tipos de estudos epidemiológicos: conceitos básicos e aplicações na área do envelhecimento. Epidemiol. Serv. Saúde, v.12, n.4, p.189-201, 2003.

LIPP, L. K.; MARTINI, F. O.; OLIVEIRA-MENEGOTTO, L. M. Desenvolvimento, escolarização e Síndrome de Down: expectativas maternas. Paidéia, 2010.

LIPP, M. E. N. Manual do inventário de sintomas de stress para adultos de Lipp (ISSL).Casa do Psicólogo, São Paulo, 2000. 
LIPP, M. E. N.; GUEVARA, A. J. H. Validação empírica do Inventário de Sintomas de Stress (ISS). Estudo de Psicologia, 1994.

LITWIN, G. H., STRINGER, R. A. Motivation and organizational climate. Cambridge: Harvard University Press, 1968.

LORENZETTI, J.; TRINDADE, L. L.; PIRES, D. E. P.; RAMOS, F. R. S. Tecnologia, inovação tecnológica e saúde: uma reflexão necessária. Texto \& Contexto Enfermagem, v.21, n. 2, p.432-439, 2012.

MANÉ, M. A.; FERREIRA, M. P. Aplicação das dimensões culturais do projeto Globe na avaliação da liderança ética: Um estudo intercultural em Portugal e Guiné-Bissau. Globadvantage - Center of Research in International Business \& Strategy, 2014.

MARQUES, G.Q.; LIMA, M.A.D.S. Organização tecnológica do trabalho em um pronto atendimento e a autonomia do trabalhador de enfermagem. Revista da Escola de Enfermagem, v.42, n.1, p.41-47, 2008.

MARTINS, M. C. F.; OLIVEIRA, B.; SIlVA, C. F.; PEREIRA, K. C.; SOUSA, M. R. Construção e validação de uma escala de medida de clima organizacional. Ver. Psicol. Organ., v.4, n.1, p.37-60., 2004

MELLO, R.C.C.; REIS, L.B.; RAMOS, F.P. Estresse em Profissionais de Enfermagem: Importância da Variável Clima Organizacional. Univ. Fed. Juiz Fora, 2018.

MELO, L.P.; CARLOTTO, M.S. Prevalence and Predictors of Burnout among Firefighters. Psicologia: Ciência e Profissão, 2016.

MELO, M.V.; SILVA, T.P.; NOVAIS, Z.G.; MENDES, M.L.M. Estresse dos profissionais de saúde nas unidades hospitalares de atendimento em urgência e emergência. Capa, v.1, n.2, 2013.

MENDES, E. V. As políticas de saúde no Brasil nos anos 80: a conformação da reforma sanitária e a construção da hegemonia do projeto neoliberal. In: Mendes, Eugênio Vilaça (Org.). Distrito sanitário: o processo social de mudança das práticas sanitárias do Sistema Único de Saúde. 3.ed. São Paulo: Hucitec. p.19-85.1995.

MENEZES, I. G.; SAMPAIO, L. R.; GOMES, A. C. P.; TEIXEIRA, F. S.; SANTOS, P. S. Escala de clima organizacional para organizações de saúde: desenvolvimento e estrutura fatorial. Estudos de Psicologia, v. 26, n. 3, p. 305-316, 2009. 
MINOZZO, F.C.; FACHINA, R.J.F.G.; GUEDES JR, D.P.; SILVA BENEDITO, A.A.; VANCINI, R.L.; LIRA, C.A.B.; GOMES, A.C.; SILVA, A.C. Periodização do treinamento de força: uma revisão crítica. Rev. bras. ciênc. mov;v.16, n.1, p.89-97, 2008.

MIQUELIM, J.D.L.; CARVALHO, C.B.O.; GIR, E.; PELÁ, N.T.R. Estresse nos profissionais de enfermagem que atuam em uma unidade de pacientes portadores de HIV-AIDS. J bras Doenças Sex Transm 16(3): 24-31, 2004.

MUROFUSE, N. T.; ABRANCHES, S. S.; NAPOLEÃO, A. A. Reflexões sobre o estresse e “Burnout" e a relação com a enfermagem. Revista Latino-Americana de Enfermagem, v.13, n.2, p. 255-261, 2005.

NEVES, J. L. Pesquisa qualitativa: características, usos e possibilidades. Cadernos de Pesquisas em Administração, v.1, n.3, 1996.

OliveIRA, D. A.; GONÇALVES, R. S.; BARBOSA, A. C. Q. Percepção dos gestores de recursos humanos em relação ao modelo de gestão por competências. Revista FSA, v.11, n.2, p. 1-26, 2014.

OLIVEIRA, L.C.; OLIVEIRA, L. ESTRESSE DA EQUIPE DE ENFERMAGEM NO AMBIENTE DE UTI. Monografia apresentada ao Programa de Aprimoramento Profissional/SES, elaborada no Complexo Hospitalar Padre Bento de Guarulhos, 2013.

ORGANIZAÇÃO MUNDIAL DA SAÚDE (OMS). Estresse no ambiente de trabalho cobra preço alto de indivíduos, empregadores e sociedade. OMS, 2016. Disponível em: http://www.paho.org/bra/index.php?option=com_content $\& v i e w=$ article\&id=5087\%3Aestresse-

no-ambiente-de-trabalho-cobra-preco-alto-de-individuos-empregadores-esociedade\&Itemid=839. Acessado em: 17/01/2017.

PASCHINI, S. Estratégia: alinhando cultura organizacional e estratégia de RH à estratégia de negócios. Rio de Janeiro: Qualitymark, 2006.

PASSOS, J.B; SILVA, E.L.; CARVALHO, M.M.C.C. Estresse no centro cirúrgico: uma realidade dos profissionais de enfermagem. Capa, v. 11, n. 2, 2010).

PAYNE, R. L.; MANSFIELD, R. Relationship of perceptions of organizational climate to organizational structure, context e hierarchical position. Administrative Science Quarterly, n. 18, p. 515-526, 1973. 
PAZ, M.G.T.; NEIVA, E.R. O poder discriminante da escala de configuração do poder organizacional na perspectiva macro organizacional e sua utilização como instrumento de caracterização do perfil cultural das organizações. Rev. Psicol., v.14, n.2, 2014.

PEREIRA, E.F.; TEIXEIRA, C.S.; ANDRADE, R.D.; SILVA-LOPES, A. O trabalho docente e a qualidade de vida dos professores na educação básica. Rev. salud pública, v.16, n.2, pp. 221-231, 2014.

PETTIGREW, A. On studying organization cultures. Administrative Science Quarterly, n.6, p.395-420, 1979.

PICKINA, T.A.M. Cultura organizacional context de mudança organizacional. Monografia apresentada na Faculdade de Economia, Administração, Contabilidade e Ciência da Informação e Documentação (FACE) da Universidade de Brasília (UnB), em cumprimento às exigências do curso de Pós-Graduação, Lato Sensu, para obtenção do título de Especialização em Gestão de Programas e Projetos Educacionais. Brasília, 2008.

PIOVESAN, A.; TEMPORINI, E.R. Pesquisa exploratória: procedimento metodológico para o estudo de fatores humanos no campo da saúde pública. Ver. Saúde publica, v.29, n.4, p.318$25,1995$.

PIRES, J. C. S.; MACÊDO, K. B. Cultura organizacional em organizações públicas no Brasil. Revista de Administração Pública, v.1, n.40, p. 81-105, 2006.

POLIT, D.F.; BECK, C.T.; HUNGLER, B.P. Fundamentos de Pesquisa em Enfermagem: métodos, avaliação e utilização. 5 ed. Porto Alegre: Artmed, 2004.

PORTElA, N. L. C.; PEDROSA, A. O.; GOMES, R. N. S.; CUNHA, J. D. S.; MONTE, L. R. S.; LAGO, E. C. Síndrome de burnout em profissionais de enfermagem de serviços de urgência e emergência. Revista de Pesquisa: cuidado e fundamental, v.7, n.3, p. 2749-2760, 2015.

PUENTE-PALACIOS, K. E.; PACHECO, E. A.; SEVERINO, A. F. Clima Organizacional e Estresse em Equipes de Trabalho. Revista Psicologia: Organizações e Trabalho, v.13, n.1, p 37-48, 2013.

RIZZATTI, G. Categorias de análise de clima organizacional em universidades federais brasileiras. Florianópolis. Tese (Doutorado). Departamento de Engenharia de Produção e Sistemas, Universidade Federal de Santa Catarina, 2002. 
RODRIGUES, J. L. K.; COSTA, S. O.; LIMA, T. J. B.; COELHO, F. A.; SILVA, J. L. G.; SANTOS, N. M. B. F. A importância da pesquisa do Clima Organizacional para o funcionamento de uma Instituição Federal de Ensino Superior. Revista Eniac Pesquisa, v. 5, n. 1, p. 29-46, 2016.

SANTOS, J. N.; NEIVA, E. R.; ANDRADE-MELO, E. A. Relação entre Clima Organizacional, Percepção de Mudança Organizacional e Satisfação do Cliente. Psicologia: Teoria e Pesquisa, v.29, n.1, p. 31-39, 2013.

SANTOS, J.V.; GONÇALVES, G.A. Cultura organizacional: o impacto visível de uma dimensão invisível. Psico, PUC-RS, 41(3), 393-398, Porto Alegre 2010.

SANTOS, N.M.; BRONZO, M.; OLIVEIRA, M.P.V; RESENDE, P.T.V. Cultura Organizacional, Estrutura Organizacional e Gestão de Pessoas como Bases para uma Gestão Orientada por Processos e seus Impactos no Desempenho Organizacional. Brazilian Business Review, v.11, n.3, p.106-129, 2014.

SBRAGIA, R. Um estudo empírico sobre clima organizacional em instituições de pesquisa. Revista de Administração, v. 18, n. 2, p. 30-39, 1983.

SCHEIN, E H. Guia de sobrevivencia da Cultura Corporativa. 2007

SCHEIN, E.H. How can organizations learn faster?: the problem of entering the green room. Ed. Spring, 1992.

SCHEIN, E.H. The corporate culture survival guide. Jossey-Bass books, San Francisco, 2009

SCHNEIDER, B.; EHRHART, M. G.; MACEY, W. H. Organizational Climate and Culture. Annu. Rev. Psychol, v.64, p. 361-388, 2013.

SCHNEIDER, B.; REICHERS, A. E. On the etiology of climates. Personnel Psychology, v.36, p.19-39, 1983.

SELYE, H. A syndrome produced by diverse nocuous agentes. Nature, v.138, p.32, 1936.

SEMEDO, D.S.R.; PELZER, M.T.; VENTURA, J.; PAULA, S.F.; MONIZ, A.S.B.; SEMEDO, J.A.C. Profile of nurses from Cape Verde/Africa: the influencing factors of life quality. Revista de Pesquisa, v 10, n.4, 2018.

SILVA, N. N. Amostragem probabilística. São Paulo: EDUSP, 2001.

SILVA, N. T. Clima organizacional: uma proposta dos fatores a serem utilizados para avaliação do clima de uma instituição de ensino superior. Tese de Mestrado, UFSC, Florianópolis, SC, 2003. 
SILVEIRA J. Brasileiros estão entre os mais estressados do globo. Folha.com, equilíbrio e saúde. 2010. Disponível em: http://www1.folha.uol.com.br/equilibrioesaude/766692-brasileirosestao-entre-os-mais-estressados-do-globo.shtml. Acessado em: 17/01/2017.

SMIRCICH, L. Concepts of Culture and Organizational Analysis. Administrative Science Quarterly, vol. 28, no. 3, pp. 339-358, 1983.

SOUSA, M.B.C.; SILVA, H.P.A.; GALVÃO-COELHO, N.L. Resposta ao estresse: I. Homeostase e teoria da alostase. Estud. psicol., v.20, n.1, 2015.

SOUZA E. L. P. Clima e cultura organizacionais: como se manifestam e como se manejam. São Paulo: Edgard Blucher, 1978.

SOUZA, E. L. P. Clima e estrutura de trabalho. Revista de Administração, v. 18, n. 3, p. 68$71,1983$.

SOUZA, E. L. P. Clima e motivação em uma empresa estatal. Revista de Administração de Empresas, v. 22, n. 1, p. 18-38, 1982.

SOUZA, E. L. P. Diagnóstico de clima organizacional. Revista de Administração Pública, v. 11, n. 2, p. 141-58, 1977.

SOUZA, E. L. P. Percepção de clima conforme escalão hierárquico. Revista de Administração de Empresas, v. 20, n. 4, p. 51-56, 1980.

TACSI, Y.R.; VENDRUSCOLO, D.M. Nursing assistance in pediatric emergency services. Rev. Lat. Am. Enfermagem, v.12, n.3, pp. 477-84, 2004.

TAVARES, W.; EVA, K. W. Exploring the impact of mental workload on rater-based assessments. Advances in Health Sciences Education, v.12, n.2, p.291-303, 2012.

TRICE, H. M.; BEYER, J. M. The cultures of work organizations. The Executive, v.6, n.3, 1993.

TRINDADE, L. L.; LAUTERT, L. Syndrome of Burnout among the workers of the Strategy of Health of the Family. Rev. Esc. Enferm, v. 44, n. 2, p. 274-249, 2010.

WEHBE, G.; GALVÃO, C.M. O enfermeiro de unidade de emergência de hospital privado: algumas considerações. Revista Latino-Americana de Enfermagem, v.9, n.2, 2001.

WEI, S. Y.; SAMIEE, S.; LEE, R. P. The influence of organizational culture, market responsiveness, and product strategy on firm performance in an emerging market. Journal of the Academy of Marketing Science, v.42, n.1, p.49-70, 2014 